\title{
COMPARISON OF TWO WOOD FILLER TYPES WITH RESPECT TO RELATIVE SHRINKAGE ACROSS VARIATIONS IN TEMPERATURE, IN HUMIDITY, AND WITHIN WOOD SPECIES
}

\author{
By \\ Joshua Lee Ellis \\ A Thesis \\ Submitted to the \\ Faculty of the Graduate School \\ of \\ Western Carolina University \\ in Partial Fulfillment of the \\ Requirements for the Degree \\ of \\ Master of Science in Technology
}

Committee:

Director

Dean of the Graduate School

Date:

Summer 2011

Western Carolina University

Cullowhee, North Carolina 


\section{COMPARISON OF TWO WOOD FILLER TYPES WITH RESPECT TO RELATIVE SHRINKAGE ACROSS VARIATIONS IN TEMPERATURE, IN HUMIDITY, AND WITHIN WOOD SPECIES}

A thesis presented to the faculty of the Graduate School of Western Carolina University in partial fulfillment of the requirements for the degree of Master of Science in Technology.

By

Joshua Lee Ellis

Director: Dr. Aaron K. Ball

Professor of Engineering Technology

Kimmel School Department of Engineering Technology

Committee Members: Dr. Wes Stone, Engineering Technology Dr. Chip Ferguson, Engineering Technology

June 2011

C 2011 by Joshua Lee Ellis 


\section{Acknowledgements}

Special thanks to my committee composed of Dr. Aaron Ball, Dr. Wes Stone, and Dr. Chip Ferguson. Specifically, I would like to thank Dr. Aaron Ball for his lifelong commitment to delivering education to students. I have had many teachers throughout my educational career, but none quite like Dr. Aaron Ball. Dr. Aaron Ball is "one of a kind" and it was an honor to have him as a mentor. Dr. Aaron Ball has truly helped me realize that the only person that can stop you from accomplishing your dreams is yourself.

I would like to thank Ken Ellington, Larry Cox, Lex Ramey and associates for permission to access work facilities, frequently throughout this research, at Shaw Industries Group located in Franklin and Bryson City, North Carolina. Also, Western Carolina University and Asheville-Buncombe Community College and Technical Institute for access to facilities and equipment required throughout this research.

I would like to thank my family, friends, and colleagues for having confidence in me throughout my educational journey. Special thanks to my wife LeAnn for love, support, and commitment throughout our journey of life together. I would like to tell my son, Corey Ellis, and future kids that you can accomplish any dream by working hard and never giving up. Corey, thank you for everything you have taught me and the sacrifices you made as a child to help us get to where we are today. To my mom, Belinda Dawn Edwards, she always told me that you can accomplish anything you put your mind to. To my Dad, Freddie Ray Ellis, the road has been curvy, but I can finally see the straight away ahead. Life is a continuous cycle where we all learn from each other. I would like to thank all my brothers and family for the life lessons they have taught me growing up. Believe in yourself, believe and you shall achieve! Life is too short, so learn as much as possible while taking time to enjoy it.

I would last and foremost like to thank God for guidance throughout life. Through God all things are possible. Mark, Rita, Pawpaw Freddie, and others I know you are smiling from above. 


\section{TABLE OF CONTENTS}

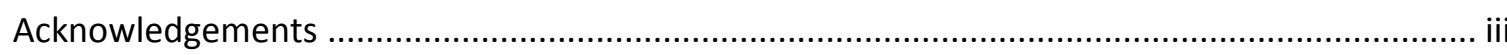

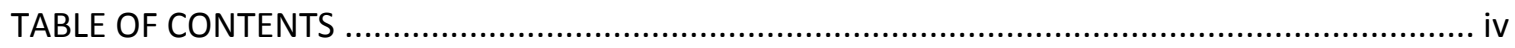

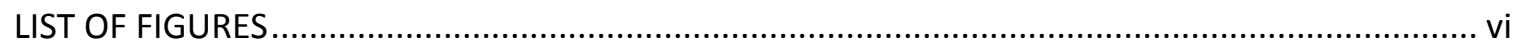

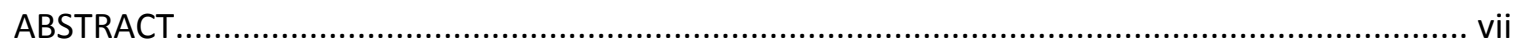

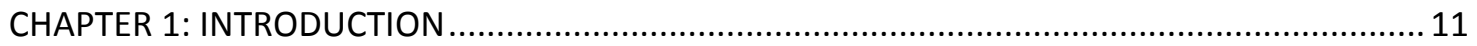

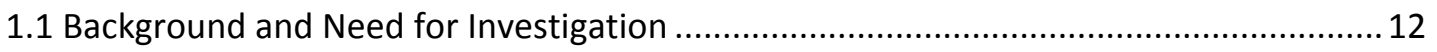

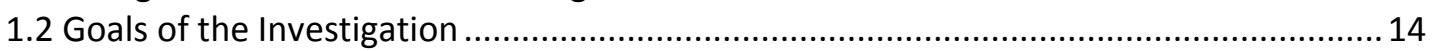

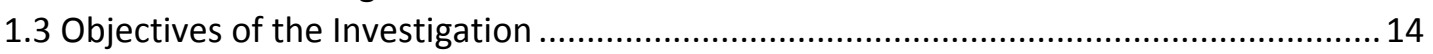

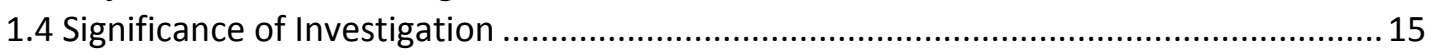

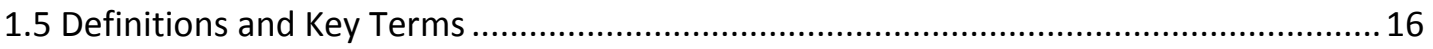

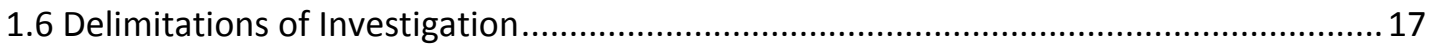

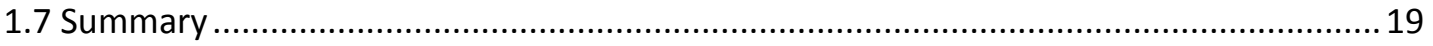

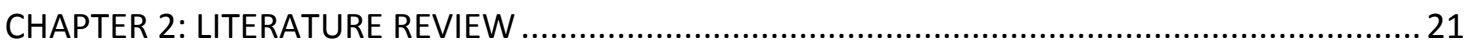

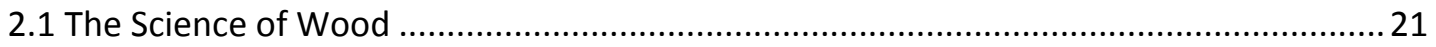

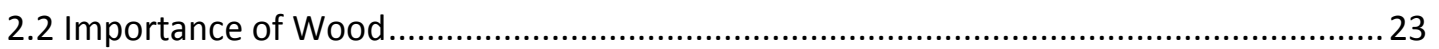

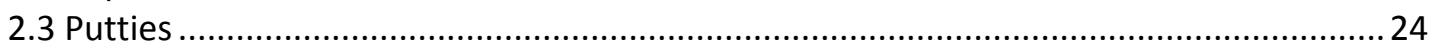

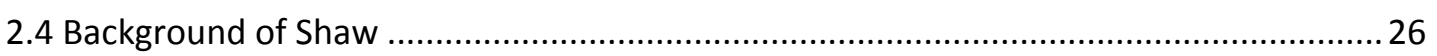

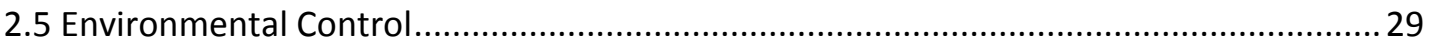

2.6 Computer Numerical Control \& Coordinate Measuring Machines ................................. 30

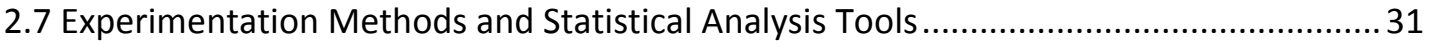

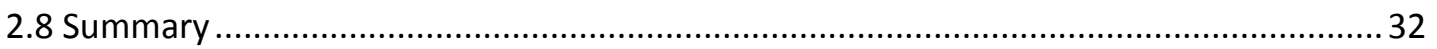

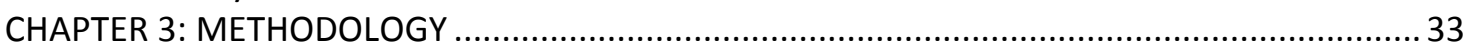

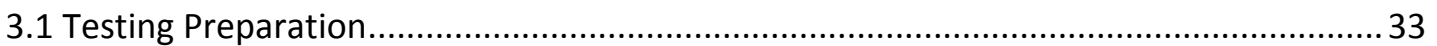

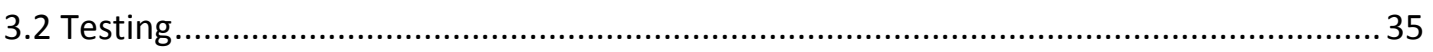

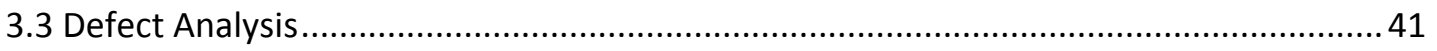

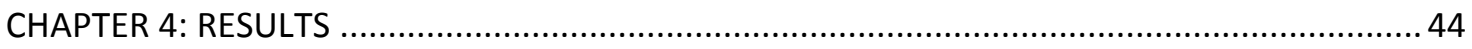

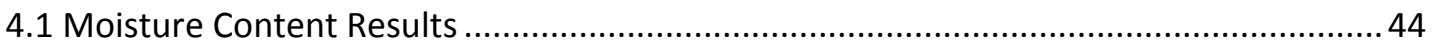

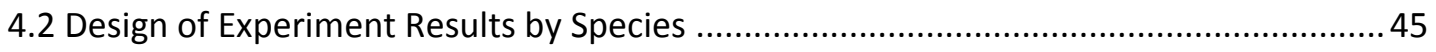

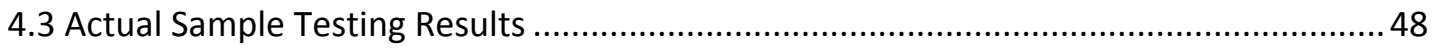

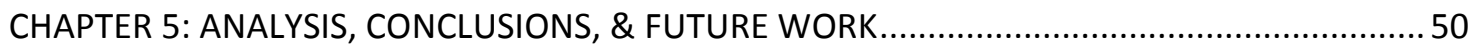

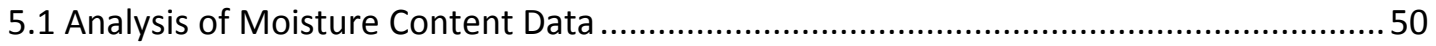

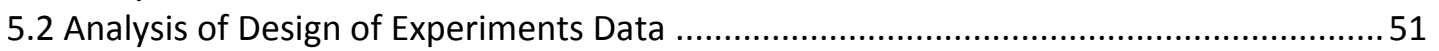

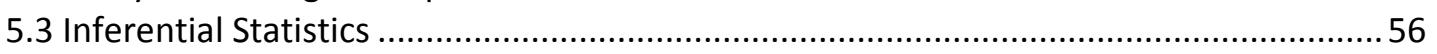

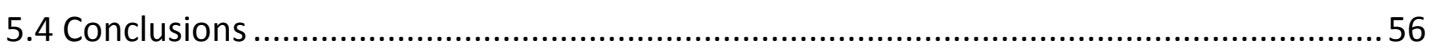

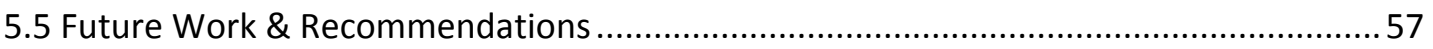

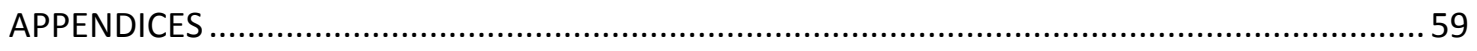

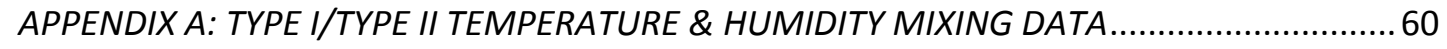

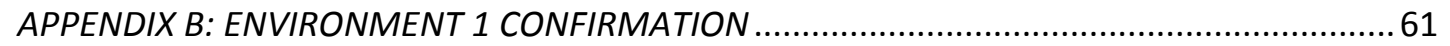

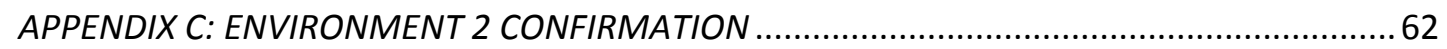

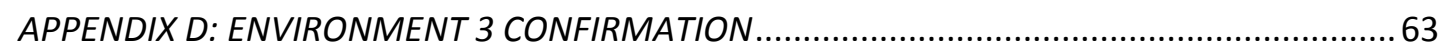

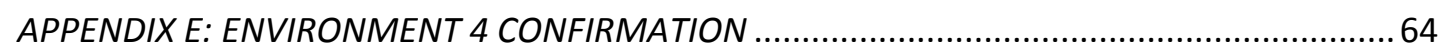

APPENDIX F: AB-TECH TEMPERATURE \& HUMIDITY DATA, AFTER TESTING ...........................65 
APPENDIX G: TRANSPORTATION TEMPERATURE \& HUMIDITY DATA FROM AB-TECH TO

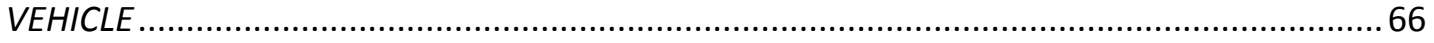
APPENDIX H: TRANSPORTATION TEMPERATURE \& HUMIDITY DATA FROM VEHICLE TO WCU

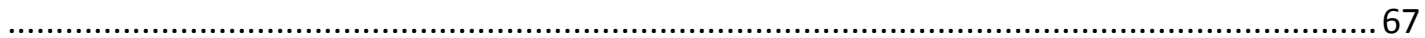
APPENDIX I: TEMPERATURE \& HUMIDITY STORAGE DATA, AFTER TRANSPORTATION .........68

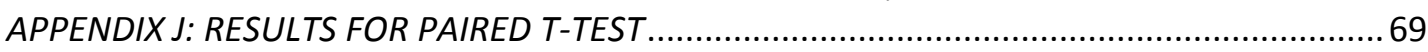

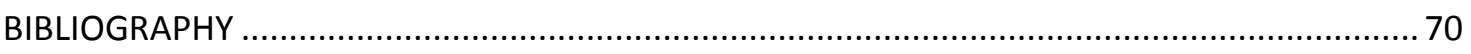

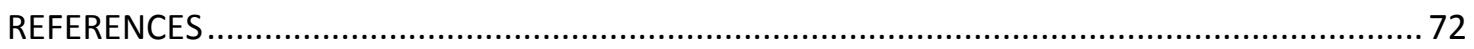




\section{LIST OF FIGURES}

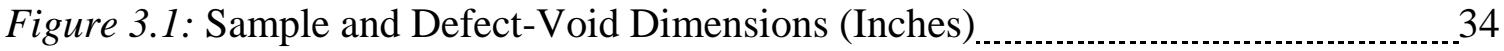

Figure 3.2: Sample Setup for Defect Machining

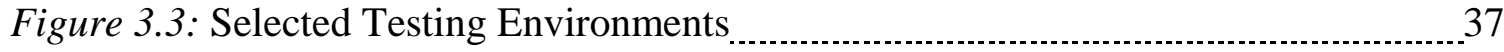

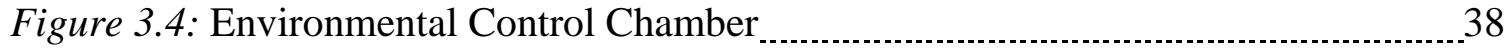

Figure 3.5: Sample Layout in Trays $\ldots$

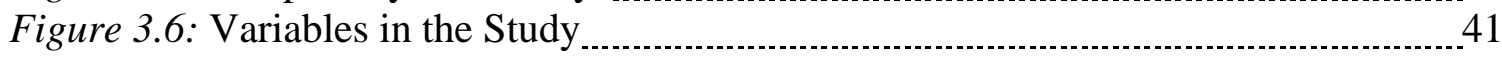

Figure 3.7: Explanation of RS

Figure 3.8: Coordinate Measuring Machine Sample Fixture _.......................................... 42

Figure 4.1: Moisture Content Results $\ldots$

Figure 4.2: ANOVA Summary for White Oak

Figure 4.3: Cube Plot for White Oak

Figure 4.4: ANOVA Summary for Red Oak

Figure 4.5: Cube Plot for Red Oak $\ldots$

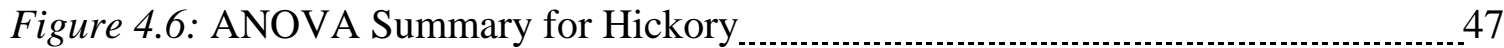

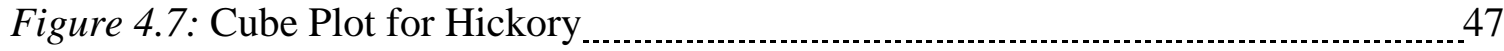

Figure 4.8: ANOVA Summary for Red Maple

Figure 4.9: Cube Plot for Red Maple

Figure 4.10: Actual Sample Testing Results _................................................. 49

Figure 5.1: ANOVA Summary Conveying Significance for Red Oak _.................... 52

Figure 5.2: Main Effects Plot for Humidity in Red Oak ..................................................53

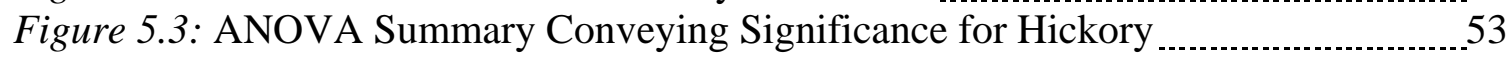

Figure 5.4: Main Effects Plot for Humidity and Putty Type in Hickory ....................... 54

Figure 5.5: Interaction Plot for Humidity and Putty Type in Hickory ........................... 55

Figure 5.6: ANOVA Summary Conveying Significance for Red Maple _..................... 55

Figure 5.7: Main Effects Plot for Humidity in Red Maple $\ldots \ldots \ldots$ 


\begin{abstract}
COMPARISON OF TWO WOOD FILLER TYPES WITH RESPECT TO RELATIVE SHRINKAGE ACROSS VARIATIONS IN TEMPERATURE, IN HUMIDITY, AND WITHIN WOOD SPECIES

Joshua Lee Ellis, M.S.T.

Western Carolina University (July 2011)

Director: Dr. Aaron K. Ball
\end{abstract}

The purpose of this research was to compare two different types of wood filler (commonly known as wood putty) with respect to fill capability and relative shrinkage across varying levels of temperature and humidity. The investigation was developed based on processing requirements set forth by Shaw Industries Group at their facility located in Franklin, North Carolina. The processing requirements for Shaw's hardwood flooring product lines governed the scope of this investigation and environmental conditions were simulated in an environmental control chamber. Characteristics of performance exhibited by the filler material are crucial for assuring the production and delivery of quality wood flooring. This research specifically focused on the investigation of relative shrinkage for two different water-based wood putty materials used for filling defects in hardwood flooring prior to finishing. Akzo Nobel brown wood putty (Type I) is currently used in Shaw's defect-void filling process and Famowood walnut filler (Type II) is proposed as an alternative for the current filling materials. Both fillers were applied to a consistent, pre-defined defect cavity volume, and evaluated based on dimensional 
changes. Each standard test cavity was produced in a laboratory setting by a Computer Numerically Controlled (CNC) machine to represent a consistent defect volume. Shrinkage data was collected using a Contura HTG coordinate measuring machine (CMM) manufactured by Zeiss, Maple Grove, Minnesota. Results showed that relative shrinkage of both wood fillers can be affected by variations in humidity while curing in the initial 1 hour set time. This research aimed to improve production quality of hardwood flooring in Western North Carolina and eliminate processing extremes at Shaw Industries Group. 


\section{CHAPTER 1: INTRODUCTION}

The purpose of this research was to compare two different types of wood filler (commonly known as wood putty) with respect to fill capability and Relative Shrinkage (RS) across varying levels of temperature and humidity. The investigation was developed based on processing requirements set forth by Shaw Industries Group (Shaw) at their facility located in Franklin, North Carolina. The processing requirements for Shaw's hardwood flooring product lines governed the scope of this investigation and environmental conditions, and were simulated in an environmental control chamber. Parameters for temperature and humidity were selected as maximum and minimum values, of material exposure encountered during actual production of wood flooring products at Shaw production facilities. Characteristics of performance exhibited by the filler material are crucial for assuring the production and delivery of quality wood flooring. This research specifically focused on the investigation of RS for two different water-based wood putty materials used for filling defects in hardwood flooring prior to finishing. The two water-based wood putty substances selected for experimentation included Akzo putty (Type I) and Famowood putty (Type II). Type I was manufactured in High Point, North Carolina by Akzo Nobel Coatings Incorporated and is water-based brown wood putty (AkzoNobel, 2010). Type II was manufactured in the United States of America (USA) by Eclectic Products Incorporated located in Pineville, Los Angeles (Eclectic, 2010). According to Eclectic Products (Eclectic, 2010), Type II is water-based filler available in ten different deviations and the variation of focus within this study was Walnut. Type I is currently used in Shaw's defect-void filling process and Type II is proposed as an alternative for the current filling materials. Both fillers were applied to a 
consistent, pre-defined defect cavity volume, and evaluated based on dimensional changes. Each standard test cavity was produced in a laboratory setting by a CNC machine to represent a consistent defect volume. Shrinkage data was collected using a CMM manufactured by Zeiss, Maple Grove, Minnesota. The goal of this study was to determine if a significant difference exists in RS between Type I and Type II putties. Specifically, wood putty materials were compared to determine the level of material volume remaining in defect-voids, after being processed in controlled temperature and humidity environments, across four different species of wood. The amount of material present in a defect-void, after being processed, was considered the RS of Type I and II. Results showed that RS of both wood fillers can be affected by variations in humidity while curing in the initial 1 hour set time. This research aimed to improve production quality of hardwood flooring in Western North Carolina and eliminate processing extremes at Shaw. This current study was conducted in collaboration with Shaw. This company was in the process of selecting different putty types with the capability of providing a higher RS than the current Type I used in the filling of defect voids. Historical information, related to Shaw, is discussed in the Background \& Need for Investigation section of this chapter.

\subsection{Background and Need for Investigation}

Shaw, headquartered in Dalton, GA, is a worldwide leader in producing flooring products (Lewis, 2008). In 2008, Shaw purchased Zickgraf Hardwood Flooring, LLC (Zickgraf) which is located in Franklin, North Carolina (K. Ellington, personal communication, March 12, 2010). Shaw purchased Zickgraf to expand their capabilities of producing hardwood flooring. The focus of this current study pertained to research, 
which may help Shaw in selecting between Type I and II materials for filling defect-voids at the Franklin hardwood flooring facility located in Franklin, NC. Testing results suggested which hardwood putty type provided the better RS given the extreme environmental conditions encountered at Shaw's plant. The company strives to continually provide the highest quality hardwood flooring to their customers (K. Ellington, personal communication, March 12, 2010). The firm recently automated all aspects in the hardwood flooring process except for the current manual putty application process. Shaw expects to double the amount of flooring produced from the new automated processes (K. Ellington, personal communication, March 12, 2010). With the new, proprietary scanner technology used in Shaw's automated processes, unacceptable defects are recognized based on dimensional standards and are cut out of the raw lumber. Acceptable lumber defects requiring putty are also recognized, defined by Shaw implementing dimensional conditions into the scanner program, while continuing to the defect-void filling process. It was important for workers performing the putty application to have a worker-friendly material that was easy to apply in a quick manner. After interviewing a group of Shaw employees who work in the putty application process, most employees agreed on their preference of Type II over Type I due to the "easier" application of the putty (S. Wood, personal communication, July 13, 2010). If statistical testing results show that Type II putty has a similar or smaller RS of Type I, statistical grounds could be provided for switching materials used in the filling of defect voids. Shaw engineers hoped to see a higher defect-fill rate with Type II seeing that most employees in the defect-void filling process prefer Type II. A smaller RS could increase the amount of product being produced and sold through the company. Shaw's yield rate, 
raw lumber purchased to product produced, fluctuates between 50 and 55 percent and Shaw engineers believe that automation in the facility coupled with the appropriate putty for the putty application process could boost the yield rate into the 60 percent range (K. Ellington, personal communication, March 12, 2010).

\subsection{Goals of the Investigation}

This research was not intended to credit nor discredit any materials tested, but was intended to assist Shaw in the production of hardwood flooring. In order for this thesis to be successful, goals identified below were satisfied throughout completion of this thesis.

- Established a database of information, pertaining to Type I and Type II putties, for Shaw to continually build upon in search of the optimum wood putty.

- Determined if RS of both filler types were affected by variations in extreme differences in temperature within each individual species tested.

- Determined if RS of both filler types were affected by variations in extreme differences in humidity within each individual species tested.

- Determined if RS of both filler types were affected by variations in extreme differences in filler type within each individual species tested.

\subsection{Objectives of the Investigation}

In order to meet the previously stated goals the following objectives included preparation of samples, materials, and testing environments; also included in this experiment was testing, storage, and analysis of samples. As performed, these objectives provided for control of variation in data collection, measurement, and analysis. Objectives are shown below. 
- Collected all hardwood samples from Shaw after being processed through facility, excluding the putty application process, to ensure relevant samples throughout experimentation.

- Prepared all hardwood samples used in testing by cutting to length and drilling consistent circular defects across all samples. Sample/defect dimensions are shown and discussed in Chapter III of this research.

- Conducted testing on all hardwood samples after meeting each required environment for testing. Testing parameters are also discussed in Chapter III of this research.

- Stored all samples together for minimum of 24 hours before transporting to WCU. Storing samples for a minimum of 24 hours was important to ensure Type I and Type II putties to be cured before transporting.

- Evaluated RS of Type I and Type II putties using a CMM located at WCU. RS is discussed in more detail within the "Definitions and Key Terms" section of this chapter.

- Presented results of this research to thesis committee and Shaw management.

\subsection{Significance of Investigation}

By increasing yield rate, profit margin and potential higher customer satisfaction can be achieved (K. Ellington, personal communication, March 12, 2010). Higher quality was achieved through more defects being properly filled. Studies show that automated manufacturing can increase savings with boosted production and less scrap (Kamrany, 1974). Implementation of automation at Shaw's Franklin, N.C. plant should force Shaw's competitors to uphold the same level of production or lose a portion of market share (K. 
Ellington, personal communication, March 12, 2010). Increased productivity should be obtainable by coupling automation with the right materials for the specified process. Increased production of hardwood flooring should be a significant benefit to the local economy of Western North Carolina as well as the region (K. Ellington, personal communication, March 12, 2010). Higher education jobs will likely be created as well as an increased flow of money into the local economy (K. Ellington, personal communication, March 12, 2010). The Western North Carolina region also has the potential to be known worldwide for Shaw's level of production along with higher quality product in the hardwood flooring production community (K. Ellington, personal communication, March 12, 2010).

\subsection{Definitions and Key Terms}

Type I- This is wood putty currently used in the putty application process at Shaw's Franklin facility. Type I is a paste-like material that is used to fill defects in hardwood flooring. Type I was manufactured in High Point, North Carolina by Akzo Nobel Coatings Incorporated and is a water-based, brown wood putty.

Type II- This is wood putty that might be used in Shaw's defect-void, filling process. Type II is also a paste-like material that is used to fill defects in hardwood. Type II was manufactured in the United States of America (USA) by Eclectic Products Incorporated located in Pineville, Los Angeles and is water-based, walnut wood putty.

Oven Dry Method (bake-out)- Process used to measure absolute moisture content of samples. Samples are weighed and placed in an oven for an allotted time period. 
Once the time period is reached, each samples weight is re-measured and the moisture content is calculated based off the before and after weights.

Surface Meter- Device that is laid parallel on top of flooring sample, where both surfaces are in contact and device measures moisture content on the surface of sample.

Yield Rate- Amount of flooring produced divided amount of raw lumber going into process.

Acceptable Defect- A defect is found to be an acceptable defect by a vision scanner that Shaw uses and is determined by user-entered data coupled with algorithms. Acceptable defects do not violate user entered conditions. Acceptable defects continue down the conveyor line to receive putty material.

Non-Acceptable Defect- A defect is found to be a non-acceptable defect by a vision scanner that Shaw uses and is determined by user-entered data coupled with algorithms. Non-acceptable defects violate user entered conditions. Nonacceptable defects continue down the conveyor line to be cut out by a chop saw. Relative Shrinkage (RS)- Average difference of 50 data points throughout defect-void, relative to top surface. RS is discussed with a visual guide in Chapter III.

\subsection{Delimitations of Investigation}

- Investigation focused on four species of hardwood which included red oak (RO), white oak (WO), hickory (H), and red maple (RM). RO, WO, H, and RM are the only species processed at Shaw's Franklin facility.

- Only two types of wood filler were analyzed throughout this study. The sole purpose in selection of Type I and Type II was due to Shaw's desire of research knowledge. 
- Given all the variables present in this study, only RS was considered when statistically analyzing data collected.

- Environmental conditions were simulated and controlled in a chamber at Asheville-Buncombe Community College and Technical Institute (AB-Tech). The purpose of controlling temperature and humidity during testing was to determine the effects of variations in each condition on RS of Type I and Type II putty materials. Selection of each environment for testing was dependent on a range of environments encountered at Shaw. The high/low settings for humidity were $60 \%$ and $90 \%$, while the high/low settings for temperature were 50 and 90 degrees Fahrenheit.

- Application of Type I and Type II putties to each sample occurred at AB-Tech and was not intended to replicate Shaw's process. Type I and Type II putties were manually applied to each defect-void using a putty knife, by one operator, in which each defect void was then visually confirmed to be properly filled.

- Finishing of each sample at Shaw's Bryson City plant was avoided to reduce the introduction of alternate variables. This finishing process would have included sanding of and staining application to all samples. Effects of variables included in the finishing process were not the focus of this thesis.

- Moisture content was an observed and non-controlled variable throughout testing. A bake-out method and surface meter device were two techniques used to analyze moisture content. Each technique is discussed within Chapter III.

- Addition of water to Type I and Type II were avoided to eliminate putty variations. At Shaw's facility, wood putty used during the application process was found in an open container. Exposure to oxygen causes the wood putty to dry over time. During 
observations, Shaw workers often added water to the wood putty to lower the viscosity, which permitted "easier" application. To eliminate continuous air flow during testing, with Type I and Type II putties, containers were temporarily opened to retrieve wood putty using an air tight dispenser. For the purpose of testing conducted for this thesis, the focus was not whether adding water to the putty would increase/decrease RS or the effects of oxygen exposure to wood putty; the focus was to determine if the RS of Type I and Type II putties was statistically different or similar. This was completed by statistically observing the effects of temperature, humidity, and filler type within each species tested.

- Given that testing occurred in an environmental control chamber, samples had to be taken out of the control chamber and transported to WCU. During this transition, samples were exposed to alternate environments from testing conditions. In an effort to reduce the introduction of alternate variables, all samples were exposed to the same conditions during transportation and were permitted a minimum of 24 hours to cure before being transported.

\subsection{Summary}

Seeing that barriers existed in the selection of putty for Shaw, this work eliminated at least one barrier and assisted in determining if Type I putty was statistically different than Type II putty. Testing results were analyzed with multiple Designs of Experiments (DOEs) to determine if environmental conditions were significant and observe interactions that occurred. Results show that humidity was significant in three out of four species of hardwood tested. Wood filler type along with the interaction between humidity and wood filler type were found to be significant in only one of the 
four species tested. Results are discussed in Chapter IV and V. Chapter II of this thesis includes a literature review. Chapter III discusses methodology and analysis techniques implemented throughout the research. Chapter IV presents results collected from testing and Chapter $\mathrm{V}$ concludes on results as well as suggesting future research related to this study and recommendations. 


\section{CHAPTER 2: LITERATURE REVIEW}

Supporting literature of this research topic is discussed and documented throughout Chapter II. Some parts of Chapter II justify the methodology conducted throughout testing, while other parts discuss current research related to this topic from other authorities. Explanations of samples, testing methods, machinery, and analysis methods are defended throughout Chapter II. Information is also included, throughout Chapter II, which argues conclusions presented in Chapter V. The literature review discussion begins with the science behind wood.

\subsection{The Science of Wood}

Wood is considered to be a natural resource since wood can be reproduced naturally by planting a seed (U.S. Department of Agriculture, 2007). No two pieces of wood will ever be exactly the same (U.S. Department of Agriculture, 2007). Wood is made up of cellulose, lignin, hemicelluloses, and small amounts of foreign materials (U.S. Department of Agriculture, 2007). A trees structure is dependent on things such as species, age, or inner growth (U.S. Department of Agriculture, 2007). Wood is a fibrous material which is composed of unfilled, extended, parallel spindle shaped cells that can affect strength, shrinkage, and grain pattern (U.S. Department of Agriculture, 2007). There is tremendous variation in the length of wood fibers within one given tree or species (U.S. Department of Agriculture, 2007). The inside of a tree is composed of the inner bark, cambium, sapwood, heartwood, pith, and wood rays (U.S. Department of Agriculture, 2007). The heartwood section of a tree is typically what products are manufactured from, seeing that the heartwood contains extractive content that gives characteristic color (Department of Agriculture, 2007). Hardwoods and softwoods are the 
two types of wood. The length of hardwood fibers are usually around 1/25 in. and softwood fibers can be between 1/8 of an inch to $1 / 3$ of an inch. Hardwoods have pores used for transporting sap longitudinally by tracheids where softwoods do not (Department of Agriculture, 2007). Tress can typically be identified by species, where physical characteristics of the tree are used as the identifier (Department of Agriculture, 2007). Wood can typically be identified by species, from identifying the color of the heartwood. White oaks have a light to dark brown color, red oaks have light brown color, hickory has a reddish brown color, and red maple has a light brownish red color (Department of Agriculture, 2007).

Wood can shrink when losing moisture or expand when gaining moisture based on the relative humidity of air, temperature of air, amount of water present in the wood, and the exchange rate/amount can be affected by species (Department of Agriculture, 2007). The amount of water present in the wood is referred to as moisture content (Department of Agriculture, 2007). Trees can hold anywhere between 30 and 200 percent moisture content. Once a tree is below the fiber saturation point, 30 percent moisture, the physical and mechanical properties of wood begin to change (Department of Agriculture, 2007). The equilibrium moisture content is achieved once the wood material can neither absorb nor lose moisture where equilibrium has been met in the environment (Department of Agriculture, 2007). Shrinkage and expansion can lead to many physical/mechanical problems depending on end use (Department of Agriculture, 2007). Tangential shrinkage in wood is typically twice as high as radial shrinkage while longitudinal shrinkage is usually not much (Department of Agriculture, 2007). Shrinkage can be affected by a number of influences including density, size, shape, drying rate 
(Department of Agriculture, 2007). Interestingly, the outer part of a tree could be shrinking, if the outer part is below the fiber saturation point, while the inner part remains the same, due to moisture content above the fiber saturation point (Department of Agriculture, 2007). Estimates of wood shrinkage can be calculated, for different species, using variables and equations supplied by the U.S. Department of Agriculture (Department of Agriculture, 2007). According to U.S. Department of Agriculture, white oak wood can shrink up to $4.4 \%$ radial, $8.8 \%$ tangentially, and $12.7 \%$ volumetric (U.S. Department of Agriculture, 2007). Red oak wood can shrink up to $4.7 \%$ radial, $11.3 \%$ tangentially, and $16.1 \%$ volumetric (U.S. Department of Agriculture, 2007). Hickory wood can shrink up to $7.0 \%$ radial, $10.5 \%$ tangentially, and $16.7 \%$ volumetric (U.S. Department of Agriculture, 2007). Red maple wood can shrink up to $4.0 \%$ radial, $8.2 \%$ tangentially, and $12.6 \%$ volumetric (U.S. Department of Agriculture, 2007). All percentages discussed for shrinkage represent the shrinkage percent from green wood to dry wood (U.S. Department of Agriculture, 2007). Wood is a material that is yet to be fully understood and with continual research the window of knowledge, pertaining to wood, should continue to evolve (U.S. Department of Agriculture, 2007).

\subsection{Importance of Wood}

New production models, for companies, are being formed worldwide due to globalization and the need for natural resources (Lindenmayer \& Franklin, 2003). Trees are natural resources, grown worldwide, sold on the market to produce goods (Lindenmayer \& Franklin, 2003). Legislation restricted harvesting increases during the mid 1960's, due to over harvesting in the 1950's (Adams \& Haynes, 2007). Forest lands in the United States of America (USA) have decreased since the early 1900's (Holechek, 
Cole, Fisher, \& Valdez, 2003). Over 307 million acres of forest land have been used in the USA since 1630 (Holechek et al., 2003). According to Timber Assessments; demand for hardwood lumber is projected to grow over the next 40 years (Adams \& Haynes, 2007). The importance of the natural resource, wood, increases with higher demand (Adams \& Haynes, 2007).

Research suggests that demand for timber in manufacturing is lowering due to the need for bio-engineered products (Lindenmayer \& Franklin, 2003). The natural quality of Shaw's products, continues to bring customers back (K. Ellington, personal communication, March 12, 2010). There are no plans for Shaw to switch from producing white oak, red oak, hickory, and red maple to any type of bioengineered product (K. Ellington, personal communication, March 12, 2010). As Shaw's Franklin plant continues to produce hardwood flooring, using every shipment of hardwood received at Shaw efficiently, is important (K. Ellington, personal communication, March 12, 2010). Therefore, much interest revolves around the natural resource, of wood, to reduce the amount wasted during manufacturing and increase the amount being sold to customers. This study enabled Shaw to analyze different manufacturing factors in an attempt to reduce the amount of scrap wood generated in Shaw's production process.

\subsection{Putties}

Putties are used commonly in industry for filling defects (Feirer, 1963), (Feirer, 1975). The most common method of applying putty is with a putty knife (Feirer, 1963). Many variations of wood putty, such as water-based or solvent-based, are available on the market (Eclectic, 2010). Shaw currently uses water-based putty due to the simplicity of cleanup (L. Cox, personal communication, July 15, 2010). Over the years, Shaw 
considered switching wood putty materials, to a higher quality material, but has not had enough research to justify a switch (K. Ellington, personal communication, March 12, 2010). Research completed at Shaw evaluated both putties in the company's process, and defects are not consistent, where testing results could be influenced by size and shape of defect void (L. Cox, personal communication, July 15, 2010). Shaw evaluated putty materials by visually confirming the defect-void to be properly or improperly filled (L. Cox, personal communication, July 15, 2010). This research developed a standard testing procedure for both putties to be compared and evaluated against each other. Both putty materials were essentially tested due to Shaw's need (K. Ellington, personal communication, March 12, 2010).

The two water-based wood putty substances selected for experimentation included Akzo Nobel Coatings Incorporated's brown wood putty (Type I) and Eclectic Products Incorporated's walnut putty (Type II). Type I was manufactured in High Point, North Carolina and is a water-based putty (AkzoNobel, 2010). Limited information could be found pertaining to Type I putty (AkzoNobel, 2010). Type II was manufactured in Pineville, Los Angeles (Eclectic, 2010). According to ECLECTIC Products (Eclectic, 2010), Type II is water-based filler available in ten different deviations and the variation of focus within this study was Walnut. Research indicates that Type II putty is fairly easy to apply, quickly to dry, hard finish, and has little to no shrinkage. Equations or specific numbers were not given on rates of shrinkage for Type II (Eclectic, 2010). Type I and Type II materials were evaluated in an effort to determine how affected by extreme environmental conditions, encountered during production, such as temperature and humidity. 


\subsection{Background of Shaw}

Shaw has proven to be a global leader in manufacturing flooring products (Lewis, 2008). Shaw is now headquartered in Dalton, Georgia after starting as Star Dye Company in 1946 (Shaw Floors, 2003). With a series of milestone expansions, such as in 1958 when the company started finishing carpet as Star Finishing Company or in 1967 when Philadelphia Carpet Company was acquired by Shaw, the company gradually transformed into the world's largest carpet manufacturer and went public as Shaw Industries, Inc. in 1971 (Shaw Floors, 2003). Years later in 1993, Shaw started a rug division and in 1998 initiated a hard surfaces division (Shaw Floors, 2003). Shaw was sold to Berkshire Hathaway Inc. in 2001, which ended the company's status as a public company (Shaw Floors, 2003).

In 2008, Shaw purchased Zickgraf which is located in Franklin, North Carolina (K. Ellington, personal communication, March 12, 2010). Zickgraf was founded in 1933 by W.C. Zickgraf and was a saw mill that employed 18 people (Lewis, 2008). Prior to Zickgraf's sale to Berkshire Hathaway Inc., with a total of 50 plus acres and an average of 250 employees, Zickgraf was the largest employer in Franklin (Lewis, 2008). Shaw purchased Zickgraf to expand their capabilities of producing hardwood flooring (K. Ellington, personal communication, March 12, 2010). In an effort for Berkshire Hathaway Inc. to position their company as a premium competitor, Shaw has recently undergone many hardware upgrades (K. Ellington, personal communication, March 12, 2010).

Upgrades at Shaw's Franklin, N.C. plant include implementation of automated product lines controlled by a proprietary vision system (K. Ellington, personal 
communication, March 12, 2010). Temperature and humidity are uncontrolled variables, at Shaw's Franklin manufacturing plant, that could have an impact on the quality of filling defect-voids (L. Cox, personal communication, July 15, 2010). In the production process, all hardwood flooring boards are initially sorted by length, width, species, and grade in Shaw's receiving building (L. Ramey, personal communication, June 21, 2010). Once sorted, the hardwood flooring boards are dried to a moisture content of $8 \% \pm 1 \%$ in dry kilns located around the plant (L. Ramey, personal communication, June 21, 2010). Once an order is received, the desired lumber is pulled from the yard and brought into the main plant (L. Ramey, personal communication, June 21, 2010). Hardwood flooring boards are then unloaded onto the main conveyor and each board is cut to the appropriate width (K. Ellington, personal communication, March 12, 2010). Boards cut to the appropriate width are then sent down the conveyor and pass a vision scanner (K. Ellington, personal communication, March 12, 2010). Once a board has passed by the vision scanner, defects are found using algorithms loaded in the vision scanner hardware (K. Ellington, personal communication, March 12, 2010). The algorithms are based on user entered specifications of the desired defects to be located (K. Ellington, personal communication, March 12, 2010). The vision scanner hardware can recognize the difference between an acceptable defect, which is a defect that can receive putty, and a non-acceptable defect, which is a defect that is unacceptable and has to be cut out for scrap (K. Ellington, personal communication, March 12, 2010). Once boards are through the vision scanner, boards continue down the conveyor to workstations where nonacceptable defects are cut out by automated chop saws (K. Ellington, personal communication, March 12, 2010). The automated chop saws know exactly where to cut 
based off communication data between the chop saw and vision scanner (K. Ellington, personal communication, March 12, 2010). Once the non-acceptable defects are cut out, all hardwood boards continue down the conveyor to receive tongues and grooves. Tongues and grooves are cut into the boards to assist in installation of the hardwood flooring product to help keep the boards together. Once tongues and grooves are cut into the hardwood flooring boards, the boards continue down the conveyor until the putty application station is reached (K. Ellington, personal communication, March 12, 2010). Shaw is looking to automate the putty application process, but will continue to use manual labor until capable innovative technologies are implemented (K. Ellington, personal communication, March 12, 2010). Once boards arrive at the putty application station each employee grabs a board, visually locates the defect, and physically applies putty to the defect with a standard putty knife (K. Ellington, personal communication, March 12, 2010). An employee then places the board back on the conveyor to be filtered to the loading station once all defects on a single board are filled with putty (K. Ellington, personal communication, March 12, 2010). Once each hardwood flooring board is at the loading station, employees load the boards onto a pallet and package them with plastic wrap, load the pallets onto a truck, and transport the pallets to Shaw's finishing plant in Bryson City where each hardwood flooring board is sanded and stain is applied to give the product a higher quality finish (K. Ellington, personal communication, March 12, 2010).

Investigating physical properties of two different water-based putties used for filling defect-voids in hardwood flooring products provided critical knowledge for Shaw and ultimately assisted in determining if Type II would be suitable for their hardwood 
flooring manufacturing process. Methods for generating comparable defects were established, by CNC machining a consistent defect into every sample, along with accurate methods for analyzing consistent defects. A database of shrinkage data for putty type was generated while representing effects of temperature and humidity. Shaw can continue to build upon this database until the optimum putty for their hardwood flooring process is discovered.

\subsection{Environmental Control}

Environmental control techniques have been studied for years (Grad, Rathjens, \& Rosenthal, 1971). Environmental conditions can be tricky to deal with when trying to control, but methods exist to do so (Klein \& Leung, 1976). Environmental test chambers can be used for standardized testing (Ball, Ferguson, \& Miceli, 2008). LabView ${ }^{\mathrm{TM}}$ is an accepted data acquisition program, which can be used in conjunction with control chambers to collect environmental data (Ball et al., 2008). The need for an environmental control chamber was significant enough that the Department of Energy funded Western Carolina University (WCU) to build one in conjunction with Asheville-Buncombe Community College and Technical Institute (AB-Tech) (Ball et al., 2008).

Most construction materials, for the AB-Tech control chamber, were donated by Oakridge National Laboratory (Ball et al., 2008). The control chamber consists of foam filled panels, similar to what is used in walk-in coolers (Ball et al., 2008). The control chamber is capable of controlling temperature/humidity by means of heating element, refrigeration unit, and humidification (Ball et al., 2008). The control chamber is only capable of dehumidification by opening the chamber door, due to implemented construction cost (Ball et al., 2008). The control chamber was developed specifically for 
research such as this presented (Ball et al., 2008). The control chamber was verified to meet required testing conditions throughout this research (Ball et al., 2008).

\subsection{Computer Numerical Control \& Coordinate Measuring Machines}

Computer Numerical Control (CNC) machines are commonly used for accurate and precise machining of many materials (Venuvinod \& Ma, 2004). Operators produce machining code typically in three dimensional (3D) software, where the machining code is then transferred to the $\mathrm{CNC}$ machine and appropriate tooling is setup (Venuvinod \& Ma, 2004). The operator can start the machining process, by pushing start on the CNC machine, once the material to be machined is located in the operation window (Venuvinod \& Ma, 2004). Tooling touch-offs are critical for the operator, when properly locating materials vice gripped in a CNC machine, to ensure accurate machining (Venuvinod \& Ma, 2004). CNC machines offer accurate machining, where multiple parts can be produced in a repeatable and reliable manner (Venuvinod \& Ma, 2004). An analysis method capable of analyzing CNC machined defect-voids was critical in this research to provide comparable data (K. Ellington, personal communication, March 12, 2010).

Coordinate Measuring Machines offer the ability to integrate coordinate points on 3D objects in conjunction with a computer (Dotson, Harlow, \& Thompson, 2003). Complex shapes can be analyzed using a CMM (Dotson et al., 2003). An operator can teach the CMM to measure a series of points by manually probing data collection points (Dotson et al., 2003). A data point is collected once a desired force is pushed against the CMM probe in the direction of measurement (Dotson et al., 2003). Data points collected by an operator can be re-measured automatically, in a reliable manner, across many parts 
with consistent features (Dotson et al., 2003). Part setup along with consistent features is essential for data measurement using a CMM (Dotson et al., 2003). A CMM provides the ability to collect multiple data points, from multiple parts, in an accurate and repeatable manner (Dotson et al., 2003).

\subsection{Experimentation Methods and Statistical Analysis Tools}

R.A. Fisher developed design of experiments (DOE) in the 1920's (Evans \& Lindsey, 2005). A DOE is a test that enables a comparison of two or more input variables; to evaluate a response variable (Evans \& Lindsey, 2005). DOE is a practical tool that can be used for quality improvement (Evans \& Lindsey, 2005). By completing a DOE, it enabled insignificant factors to be eliminated and significant factors to be evaluated (Evans \& Lindsey, 2005). One of the most common types of experimental designs is called a factorial experiment (Evans \& Lindsey, 2005). Factorial experiments evaluate combinations of levels for each factor where the amount of levels and factors can differ (Evans \& Lindsey, 2005). Four DOEs completed in this research were two levels and three factor experiments, which incorporated eight outcomes for each response variable (Evans \& Lindsey, 2005). A factorial experiment allows for an estimation of the effects of each factor. According to Evans \& Lindsey (2005), experiments should be randomized to eliminate bias influence (Evans \& Lindsey, 2005). Complete randomization is not always possible due to the influence of other factors during and between testing (Evans \& Lindsey, 2005). Main effects and interactions can be deemed significant if the p-value generated in the DOE is less than the implemented alpha value (Evans \& Lindsey, 2005). 
Minitab is a software package, used throughout this thesis to record and analyze data, capable of conducting a DOE (Jiju, 2004). Testing runs are typically randomized within Minitab, but was avoided to eliminate the introduction of alternate variables during testing and partially due to time constraints (Jiju, 2004). The program generates graphs that permit analysis of main effects and interactions (Jiju, 2004). The program is commonly used in Six Sigma analysis and should be capable of meeting the needs of this research (Jiju, 2004). Microsoft Excel is also a software package capable of creating visual graphs to observe data and was used periodically to do so (Microsoft, 2011).

\subsection{Summary}

Information presented throughout Chapter II justifies methodology conducted throughout this study as well as providing explanations for results presented in this research. Methodology conducted throughout this study is shown in Chapter III. Results are discussed in Chapter IV while explanations and conclusions are offered in Chapter V. This research was conducted primarily to assist Shaw in evaluating process materials, affected by environmental conditions. 


\section{CHAPTER 3: METHODOLOGY}

Testing and analysis techniques are discussed throughout this chapter. This research required a consistent cavity to compare putty types, a method to control environmental conditions, as well as a consistent analysis method to analyze all samples. A consistent cavity was machined by Computer Numerical Control (CNC) and was analyzed using a Coordinate Measuring Machine (CMM). Environmental conditions were controlled by means of a control chamber. Methodology conducted throughout this research enabled the evaluation of putty materials and environmental conditions to assist Shaw Industries Group Inc. (Shaw) of Franklin, NC in the production of hardwood flooring.

\subsection{Testing Preparation}

Shaw provided all hardwood samples and wood putty used in testing to ensure comparable materials during experimentation. Excess amounts of hardwood flooring samples were collected to ensure a suitable amount to create the appropriate number of samples for each species. White oak, red oak, hickory, and red maple were the species of hardwood investigated throughout this study. Type I and Type II putties were collected during the same time as the hardwood samples. All samples were transported under the same conditions from Shaw's plant to Western Carolina University’s Belk Building once samples were collected. Completion of a reliable study required samples to have comparable physical dimensions to permit for equivalent analysis (Dotson et al. 2003). A total of 128 samples were cut to 7.125 inches in length, using a chop saw located in the construction lab of WCU's Belk building. One inch of each sample was eventually removed to determine the true moisture content of the one inch sample, which is 
discussed later in the chapter, by conducting the bake-out at Shaw. Dimensions for each remaining 6 inch hardwood sample are specified in figure 3.1, along with defect-void dimensions. As mentioned, comparable samples and defects were important for defendable analysis.

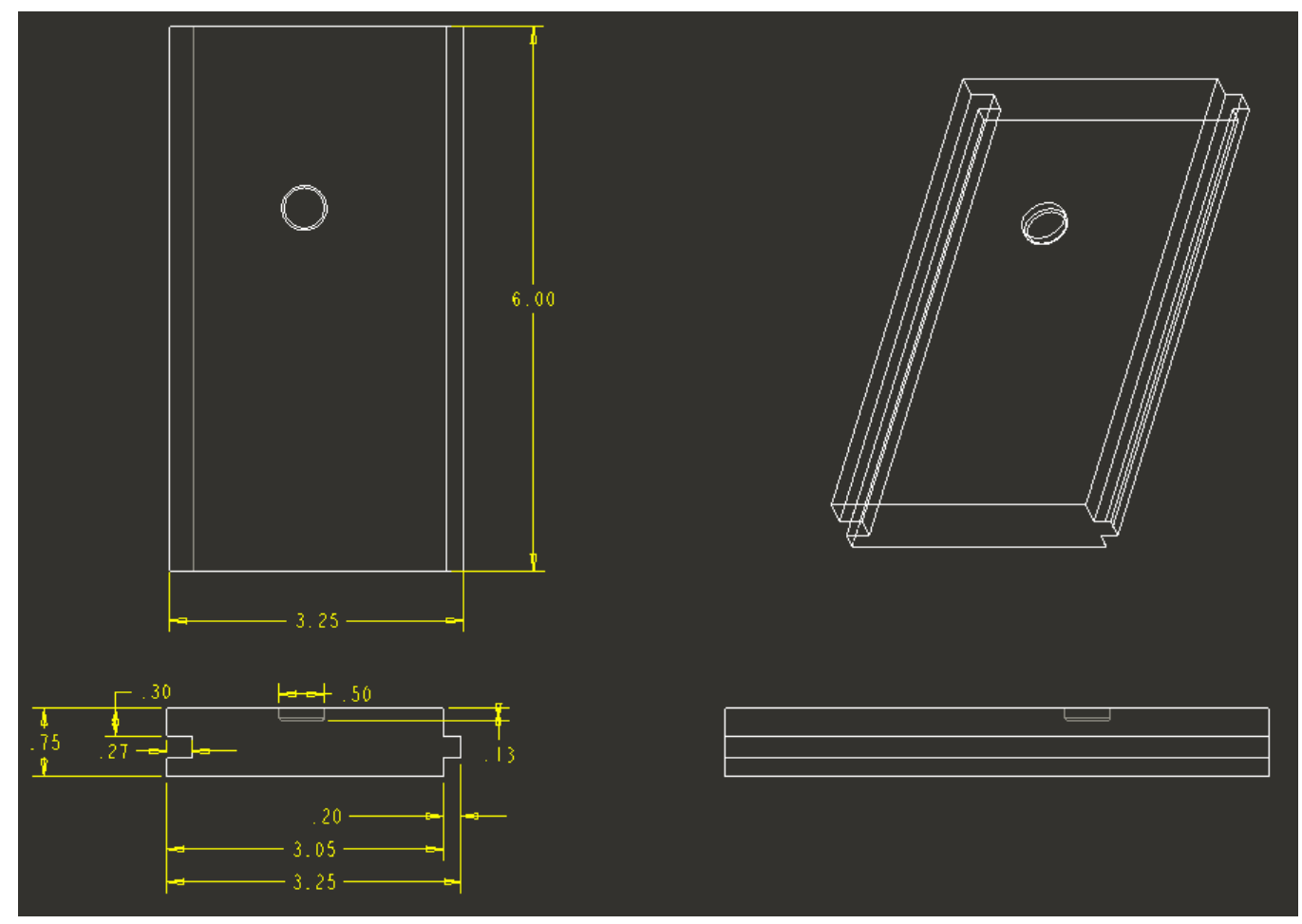

Figure 3.1: Sample and Defect-Void Dimensions (Inches).

In order to ensure comparable defects, a CNC Hass milling machine was used to mill an approved defect, by Shaw, into each hardwood flooring sample. OneCNC computer software was used to develop the program executed by the CNC Hass milling machine. All samples were setup in the CNC Hass milling machine referencing the same home position, which as shown in figure 3.2, and treated with the same program. 


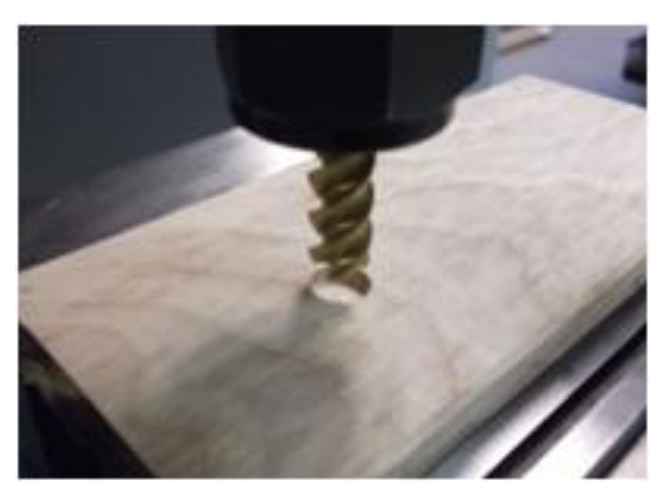

Figure 3.2: Sample Setup for Defect Machining.

A $1 / 2$ inch diameter, circular defect was milled $1 / 8$ inches deep into each hardwood flooring sample. A $1 / 2$ inch bull-nosed drill bit was plunged at a feed rate of 25 and a speed of 6500 revolutions per minute (rpm) to create the defect void. Essentially, all samples were treated the same throughout this study to allow for comparable data. Samples were label one through 128, using a maker on the back side, to keep track of each sample throughout testing and analysis. All samples were divided into four groups with a total of 32 in each tray and stacked on top of each other. Within each tray, there were four columns composed of 8 samples each whereas each column represented a different species of hardwood. Once prepared, samples remained in this location until March 1, 2011. Separating samples into four different trays, with 32 samples in each, was important. Each tray filled with samples was dedicated to a specific temperature and humidity environment, which is discussed later in this chapter.

\subsection{Testing}

On March 1, 2011, the one inch section addressed earlier in the chapter was removed from each sample. The 6 inch samples were placed back into storage and all the one inch sections were transported under the same conditions to Shaw's Franklin plant to 
conduct a bake-out. The bake-out was conducted by a trained employee at Shaw's facility. Each one inch sample was weighed while the corresponding values were recorded. All samples were then placed in a small oven and dried for 24 hours. Once the 24 hour time limit expired, samples were removed and corresponding weights were recalculated using the same measuring device. Moisture content was calculated by dividing the after weight by before weight, subtracting from one, and multiplying by 100 . Moisture content results, from Shaw's bake out process, are shown in Chapter IV. Once returning to Western Carolina University, the four trays holding all 6 inch samples were collected and transported under the same conditions to Asheville-Buncombe Community College and Technical Institute (AB-Tech). Samples were stored, in the same location, until the following morning to conduct testing.

Upon arrival to AB-Tech, Type I/Type II putties were unsealed, mixed for 60 seconds at a consistent velocity, and collected in containers. Four plastic containers were filled with an excess amount of Type I putty and four containers were filled with Type II putty. One container, of each wood putty type, was devoted to a specific temperature and humidity environment. The purpose of separating the wood putty into different containers was to reduce the exposure of oxygen throughout testing. Once the wood putty had been divided appropriately, it was important to determine the order of testing each of the four environments.

Normally the order would be randomized in testing, but order was pre-selected given time constraints of the research and setup times of the environmental control chamber. Each selected testing environment, with corresponding settings, is shown in figure 3.3 . 
- Environment 1

- Temperature: 50

- Humidity: 90

- Environment 3

- Temperature: 90

- Humidity: 60
- Environment 2

- Temperature: 50

- Humidity: 60

- Environment 4

- Temperature: 90

- Humidity: 90

Figure 3.3: Selected Testing Environments.

Environment 1 was set to have a temperature of 50 degrees Fahrenheit and a relative humidity of 60 percent. Environment 2 was set to have a temperature of 50 degrees Fahrenheit and a relative humidity of 90 percent. Environment 3 was set to have a temperature of 90 degrees Fahrenheit and a relative humidity of 60 percent.

Environment 4 was set to have a temperature of 90 degrees Fahrenheit and a relative humidity of 90 percent. Prior to testing in each environment, the target temperature and humidity were confirmed by sensors within the control chamber. Unfortunately, when the door of the control chamber opens, the chamber requires time to re-stabilize around the set temperature and humidity conditions. Therefore, a 15 minute holding period was set for the samples to be held in the control chamber, until the desired environment was satisfied. The environmental control chamber, used throughout this research, is shown below in figure 3.4. 


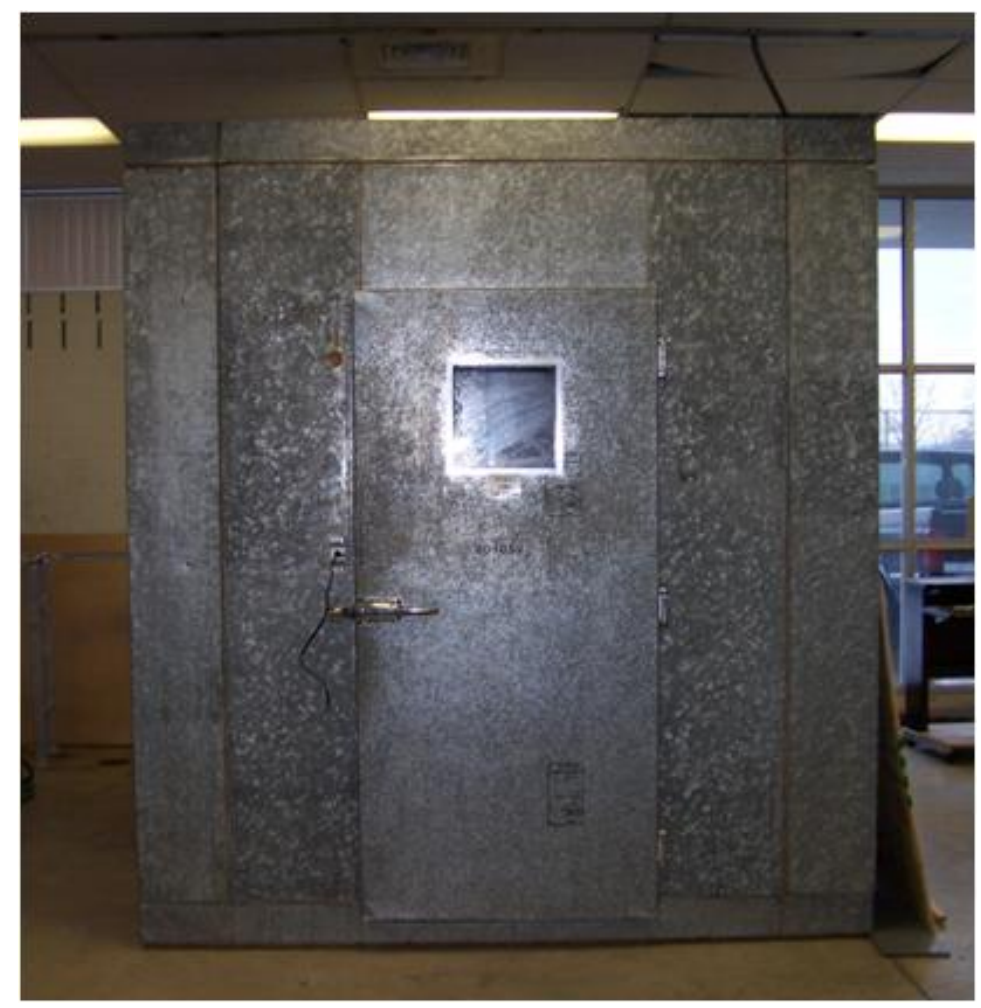

Figure 3.4: Environmental Control Chamber.

Once Environment 1 was confirmed by sensors in the control chamber, tray one was taken out of storage and relocated to the wood putty application area. The surface moisture content of all samples was measured prior to entry of the control chamber. Results for surface moisture of each sample, prior to control chamber entry, is shown in Chapter IV. One operator was used when applying wood putty to reduce variation in the method of application. Wood putty was applied, scraped, and visually confirmed to have been properly filled in each defect void. In order to apply wood putty with minimum oxygen exposure, a 60 milliliter syringe was used to apply both types of wood putty to reduce oxygen contamination. One syringe was devoted to each wood putty material. The lid was removed, from one plastic container of each wood putty type and the syringe was inserted into the wood putty materials. 
Each syringe was filled to $60 \mathrm{ml}$ of both wood putty and two milliliters of wood putty was devoted to each defect region. This process was completed a total of four times, to prepare samples for each of the four environments. Once Environment 1 samples were visually confirmed to have been properly filled, tray one was inserted into the control chamber for a holding period of 15 minutes to allow the chamber to reach desired conditions. Also, when each tray was placed in the chamber, a temperature sensor and humidity sensor was physically setup to collect data, with the exception of during the holding period. Data collected was compared to internal sensors within the control chamber to obtain a means of calibration. All sensors were placed in the same location for each of the four environmental setups. Once the 15 minute holding period had elapsed for each environment, temperature and humidity sensors were instructed to collect data. Each tray of samples required separate testing and was held for an hour each before being removed. Temperature and humidity data for each environmental run are shown in the appendices. A completed tray of samples is shown in figure 3.5, where columns represent a different species of wood, the top four rows are filled with Type I putty, and the bottom four rows are filled with Type II putty. There are a total of four replicates for each sample tested. 


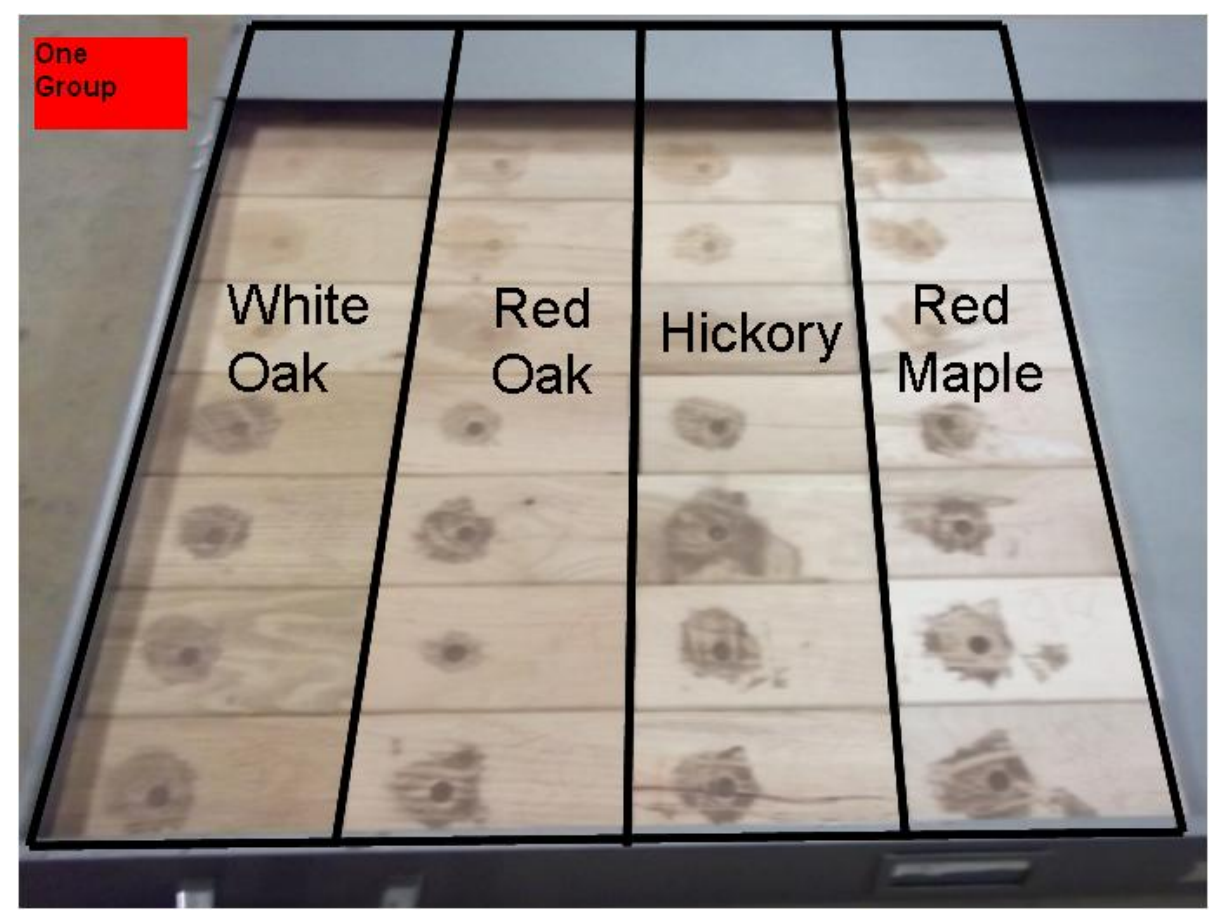

Figure 3.5: Sample Layout in Trays.

A time period of one hour was selected for testing due to time constraints and availability of the environmental control chamber. Preliminary research also suggested that the set time would take approximately one to two hours to set/harden. Therefore, no samples were removed from the corresponding test environment until the one hour time limit was reached. All samples were placed in a designated area together, outside the chamber, once a tray of samples were removed from the chamber. All samples were permitted a minimum of 24 hours to ensure Type I/Type II materials to be fully hardened/cured before transporting. All samples were then transported to Western Carolina University's (WCU) Rapid Center and stored under the same conditions until analysis was conducted. 


\subsection{Defect Analysis}

Independent and dependent variables of focus, in this research, are shown below in figure 3.6.

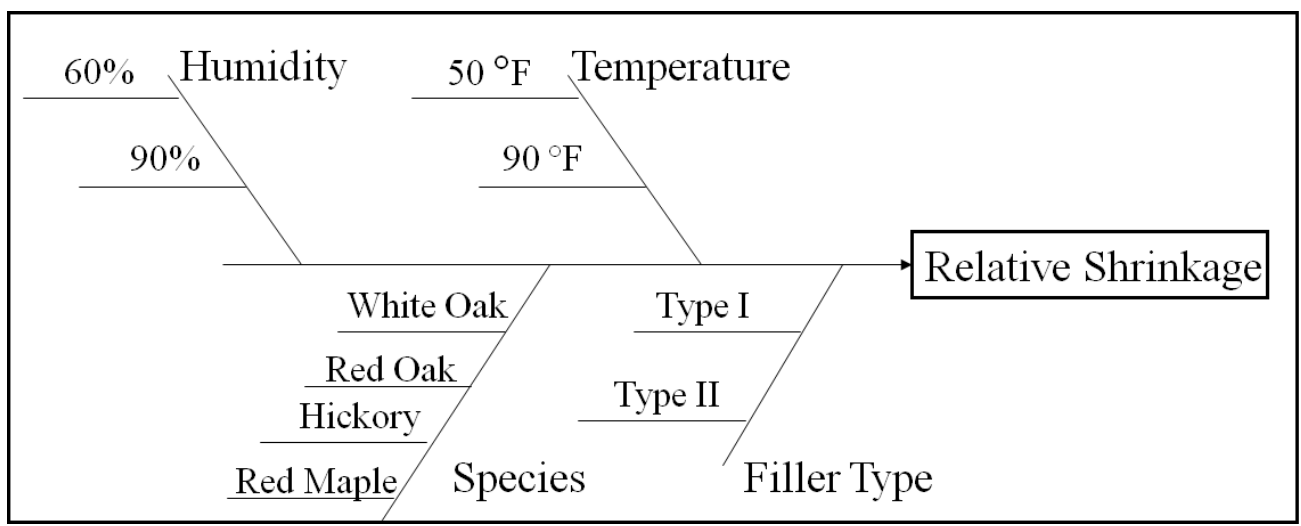

Figure 3.6: Variables in the Study.

Each sample was analyzed as RS data were collected using the CMM. RS was defined as an average of 50 depth data points throughout defect-void, relative to the top surface of the hardwood sample. An explanation of RS is shown in figure 3.7.

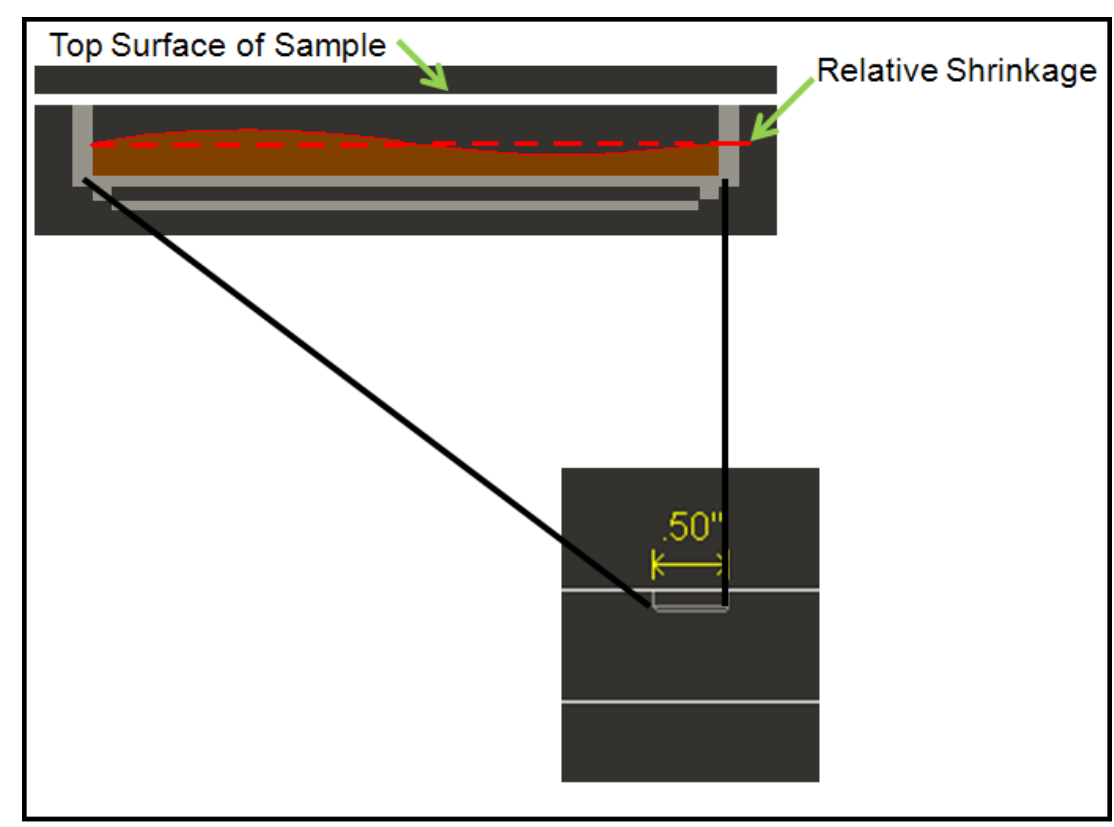

Figure 3.7: Explanation of RS. 
A CMM probe was touched off, incrementally throughout the defect-void 50 times, measuring vertical distance from the top of the sample surface to the top of the wood putty. All 50 data points were then averaged to compute RS.

A fixture, shown in Figure 3.8, was used to hold all samples in place, consistently, when measuring from sample to sample.

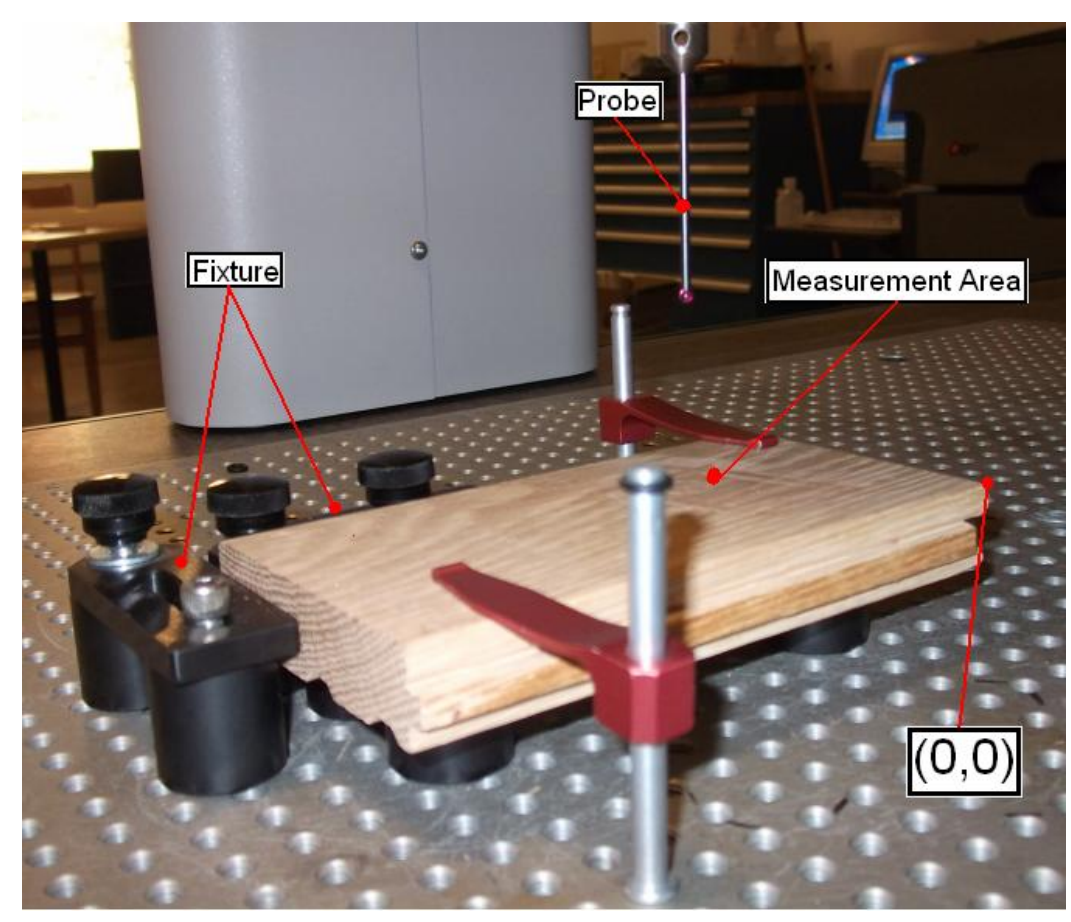

Figure 3.8: Coordinate Measuring Machine Sample Fixture.

Consistent locations of defect-voids enabled for "consist" analysis of samples, given that samples were setup in the same orientation throughout analysis. Three surfaces, on all samples, were touched off using the CMM probe upon occurrence of a new sample being inserted into the CMM fixture; this was conducted as a cautionary measure to re-teach the CMM exactly where the new sample was located, which ultimately ensured accurate measurement points across all samples. 
Data was transferred to Minitab software to perform four DOEs upon completion of collecting data from all 128 defect-voids.

DOEs were used to analyze the variation of RS within each of the four species of hardwood investigated by averaging four replicates or samples and presenting the observed averages at given input variable settings such as temperature, humidity, or putty type. Samples were essentially analyzed and concluded upon based on data that was collected, representing treatment during the one hour testing set time. The methodology shown in this chapter was critical when completing, to successfully establish a database of RS data for Shaw to continually build upon in search of the optimum wood putty. A clear methodology assisted in determining if RS is affected by variations in temperature, humidity, and/or putty type. All goals of this research were completed by meeting each of the previous discussed objectives shown in Chapter I and results for this study are shown in Chapter IV. 


\section{CHAPTER 4: RESULTS}

Methodology discussed in Chapter III was successfully completed. Results for this research are shown throughout Chapter IV and explained in-depth within Chapter V. Results are visually conveyed throughout this chapter; which included actual testing samples, moisture content results, and Design of Experiment (DOE) results. This chapter begins with moisture content results.

\subsection{Moisture Content Results}

Data shown in figure 4.1 represents moisture contents recorded throughout testing for each sample.

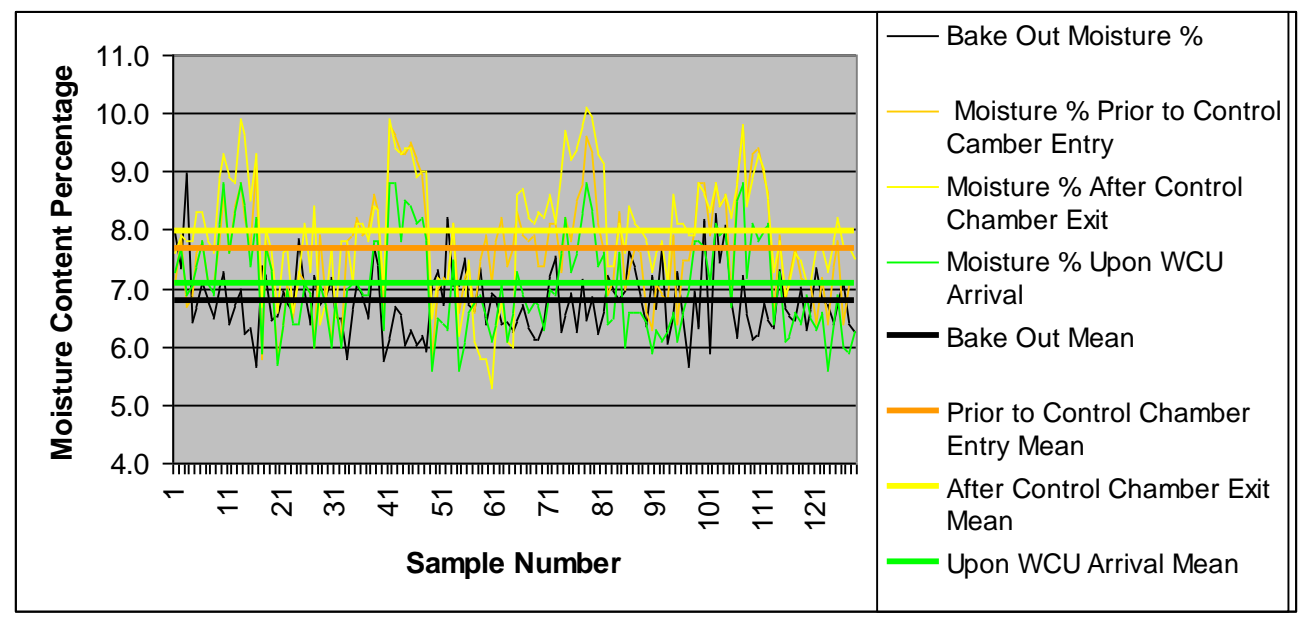

Figure 4.1: Moisture Content Results

Black data represents results from Shaw's bake-out method and other colors represent moisture content data, collected from the surface meter, during testing. Average moisture contents are given for each trial of data collection. 


\subsection{Design of Experiment Results by Species}

\section{White Oak}

An ANOVA summary, for the white oak species, is shown in figure 4.2.

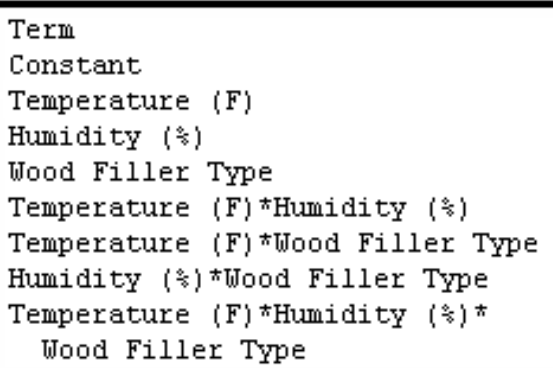

$\begin{array}{rrrrr}\text { Effect } & \text { Coef } & \text { SE Coef } & \text { T } & \text { P } \\ & -0.004894 & 0.000573 & -8.55 & 0.000 \\ 0.001925 & 0.000962 & 0.000573 & 1.68 & 0.106 \\ 0.001737 & 0.000869 & 0.000573 & 1.52 & 0.142 \\ -0.001700 & -0.000850 & 0.000573 & -1.48 & 0.151 \\ -0.001900 & -0.000950 & 0.000573 & -1.66 & 0.110 \\ -0.001312 & -0.000656 & 0.000573 & -1.15 & 0.263 \\ 0.001000 & 0.000500 & 0.000573 & 0.87 & 0.391 \\ -0.002063 & -0.001031 & 0.000573 & -1.80 & 0.084 \\ & & & & \end{array}$

Figure 4.2: ANOVA Summary for White Oak

A cube plot, for the white oak species, is shown in figure 4.3.

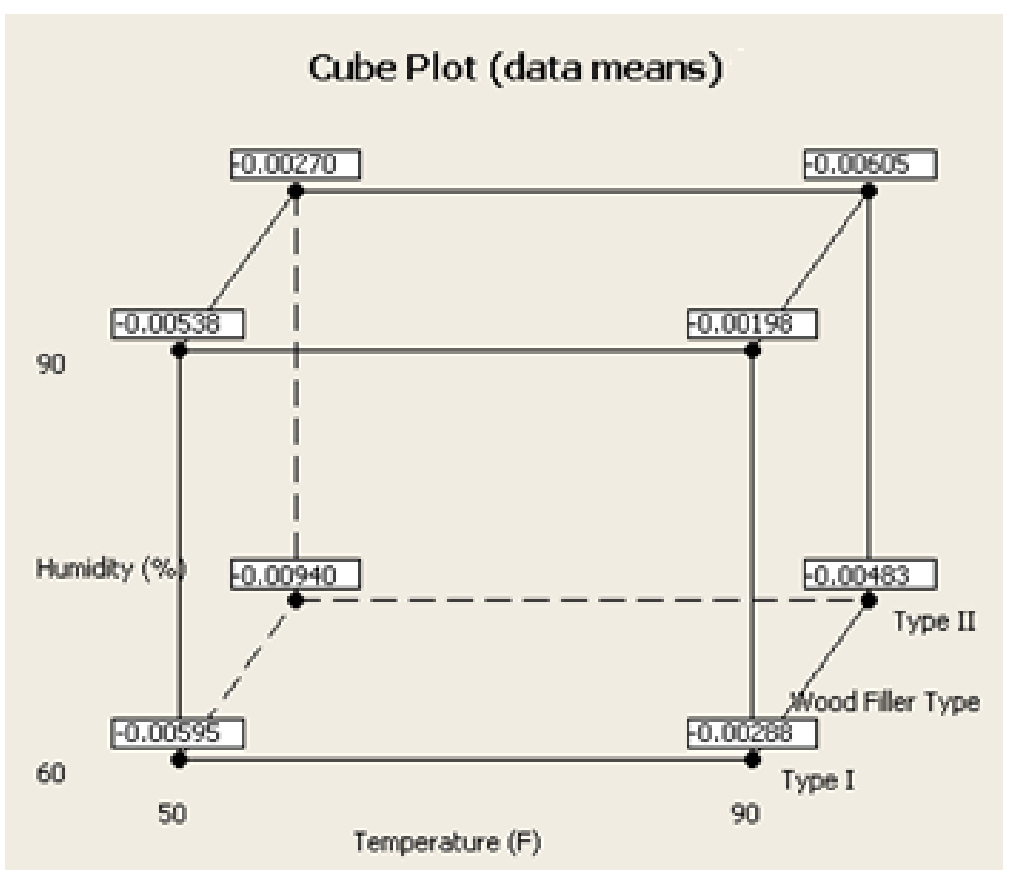

Figure 4.3: Cube Plot for White Oak 


\section{Red Oak}

An ANOVA summary, for the red oak species, is shown in figure 4.4.

\begin{tabular}{lrrrrr|}
\hline Term & Effect & Coef & SE Coef & T & P \\
Constant & & -0.004803 & 0.000798 & -6.02 & 0.000 \\
Temperature (F) & 0.000906 & 0.000453 & 0.000798 & 0.57 & 0.575 \\
Humidity (*) & -0.003931 & -0.001966 & 0.000798 & -2.46 & 0.021 \\
Wood Filler TYpe & -0.000431 & -0.000216 & 0.000798 & -0.27 & 0.789 \\
Temperature (F) *Humidity (*) & -0.000194 & -0.000097 & 0.000798 & -0.12 & 0.904 \\
Temperature (F) *Wood Filler TYpe & -0.001569 & -0.000784 & 0.000798 & -0.98 & 0.336 \\
Humidity (*) *Wood Filler TYpe & 0.000969 & 0.000484 & 0.000798 & 0.61 & 0.550 \\
Temperature (F) *Humidity (*)* & -0.000944 & -0.000472 & 0.000798 & -0.59 & 0.560 \\
$\quad$ Wood Filler TYpe & & & & & \\
\hline
\end{tabular}

Figure 4.4: ANOVA Summary for Red Oak

A cube plot, for the red oak species, is shown in figure 4.5.

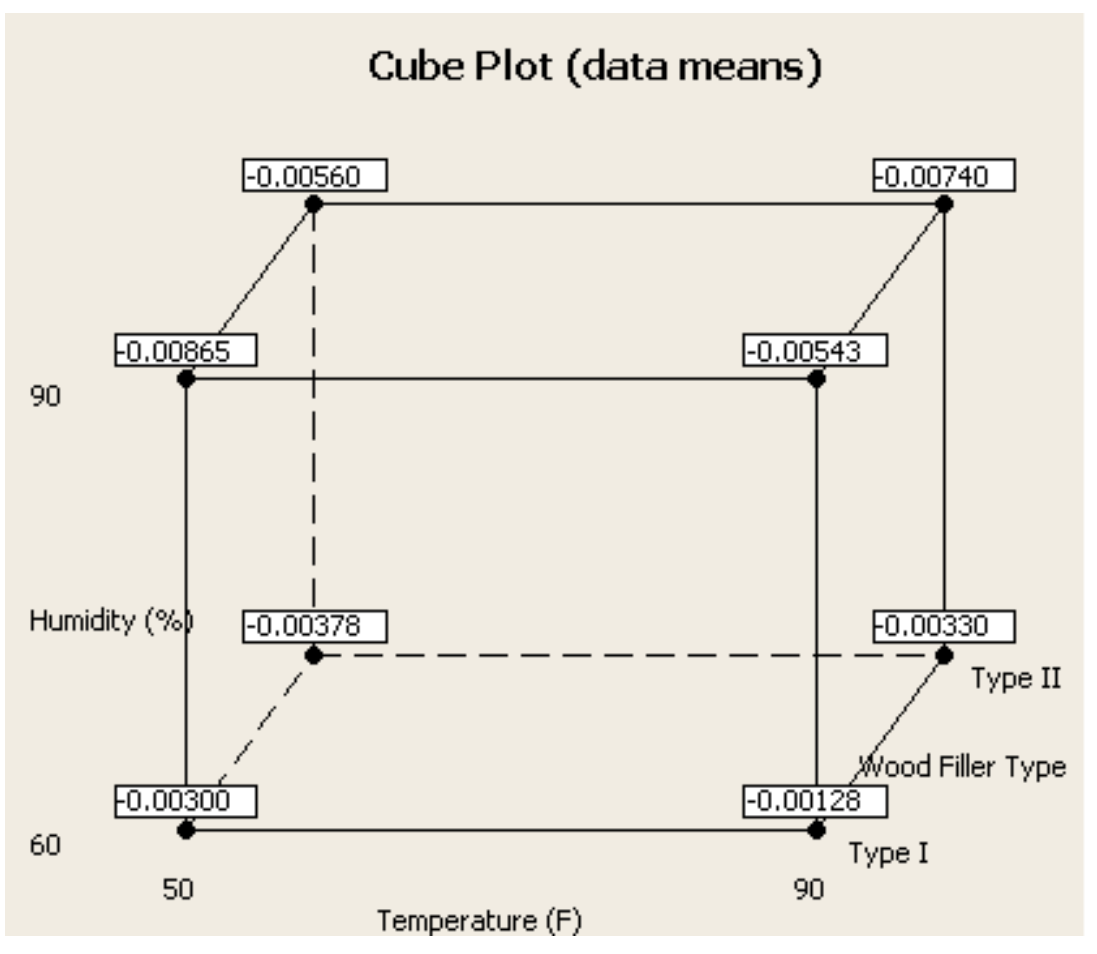

Figure 4.5: Cube Plot for Red Oak

\section{Hickory}

An ANOVA summary, for the hickory species, is shown in figure 4.6. 


\begin{tabular}{lrrrrr|} 
Term & Effect & Coef & SE Coef & T & P \\
Constant & & -0.005244 & 0.000692 & -7.57 & 0.000 \\
Temperature (F) & 0.001175 & 0.000587 & 0.000692 & 0.85 & 0.404 \\
Humidity (\$) & 0.003600 & 0.001800 & 0.000692 & 2.60 & 0.016 \\
Wood Filler TYpe & -0.003000 & -0.001500 & 0.000692 & -2.17 & 0.040 \\
Temperature (F) Humidity (\$) & 0.000587 & 0.000294 & 0.000692 & 0.42 & 0.675 \\
Temperature (F) *Wood Filler TYpe & -0.000713 & -0.000356 & 0.000692 & -0.51 & 0.612 \\
Humidity (\$) *Wood Filler TYpe & 0.005963 & 0.002981 & 0.000692 & 4.31 & 0.000 \\
Temperature (F) *Humidity (\$)* & -0.000625 & -0.000313 & 0.000692 & -0.45 & 0.656 \\
$\quad$ Wood Filler TYpe & & & & & \\
\hline
\end{tabular}

Figure 4.6: ANOVA Summary for Hickory

A cube plot, for the hickory species, is shown in figure 4.7.

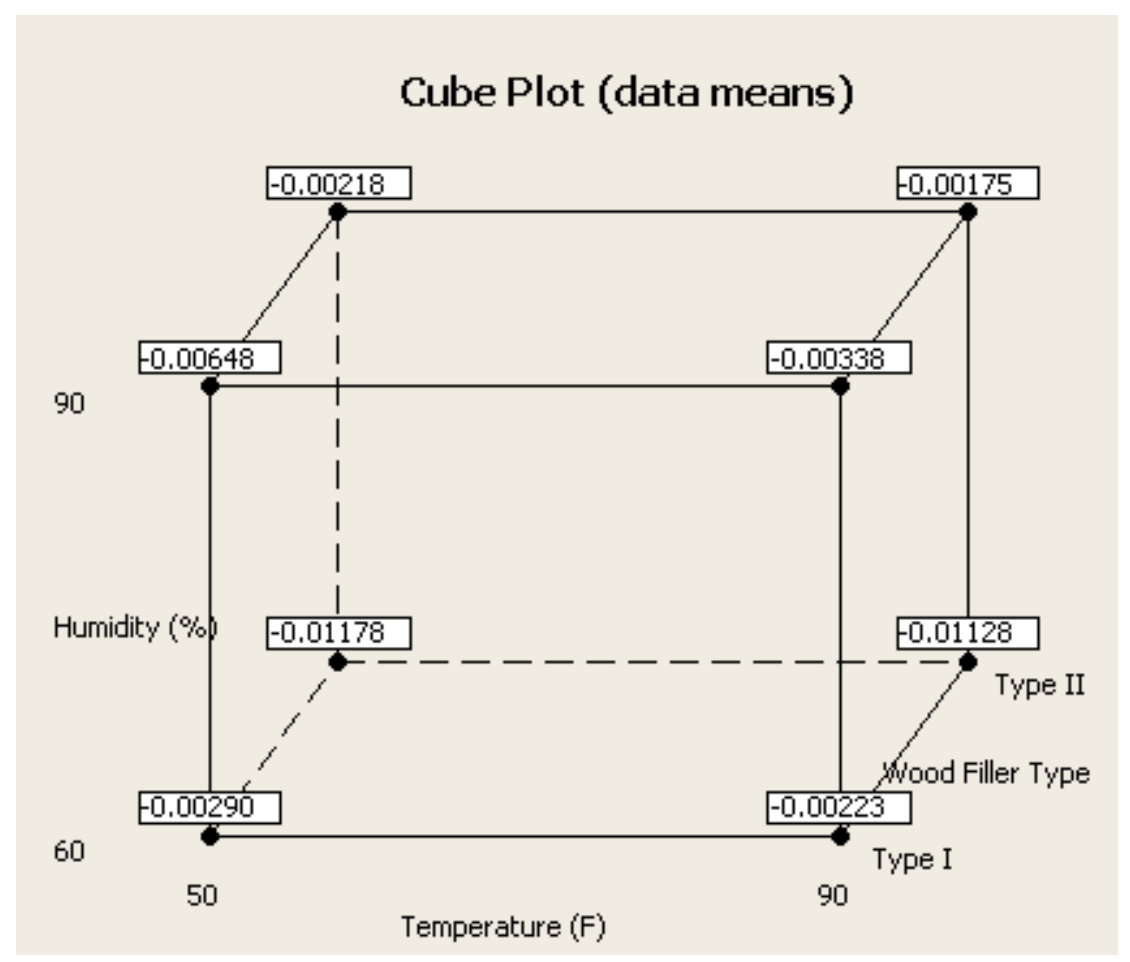

Figure 4.7: Cube Plot for Hickory

\section{Red Maple}

An ANOVA summary, for the red maple species, is shown in figure 4.8. 
Term

Constant

Temperature (F)

Humidity (후)

Wood Filler Type

Temperature (F) *Humidity (혹)

Temperature (F) Wood Filler Type

Humidity (s) thood Filler Type

Temperature (F) *Humidity (\$) * Wood Filler Type

$\begin{array}{rrrrr}\text { Effect } & \text { Coef } & \text { SE Coef } & \text { T } & \text { P } \\ & -0.005378 & 0.000634 & -8.48 & 0.000 \\ 0.001494 & 0.000747 & 0.000634 & 1.18 & 0.251 \\ 0.003619 & 0.001809 & 0.000634 & 2.85 & 0.009 \\ -0.000294 & -0.000147 & 0.000634 & -0.23 & 0.819 \\ -0.000056 & -0.000028 & 0.000634 & -0.04 & 0.965 \\ 0.000656 & 0.000328 & 0.000634 & 0.52 & 0.610 \\ -0.001444 & -0.000722 & 0.000634 & -1.14 & 0.266 \\ 0.000081 & 0.000041 & 0.000634 & 0.06 & 0.949\end{array}$

Figure 4.8: ANOVA Summary for Red Maple

A cube plot, for the red maple species, is shown in figure 4.9.

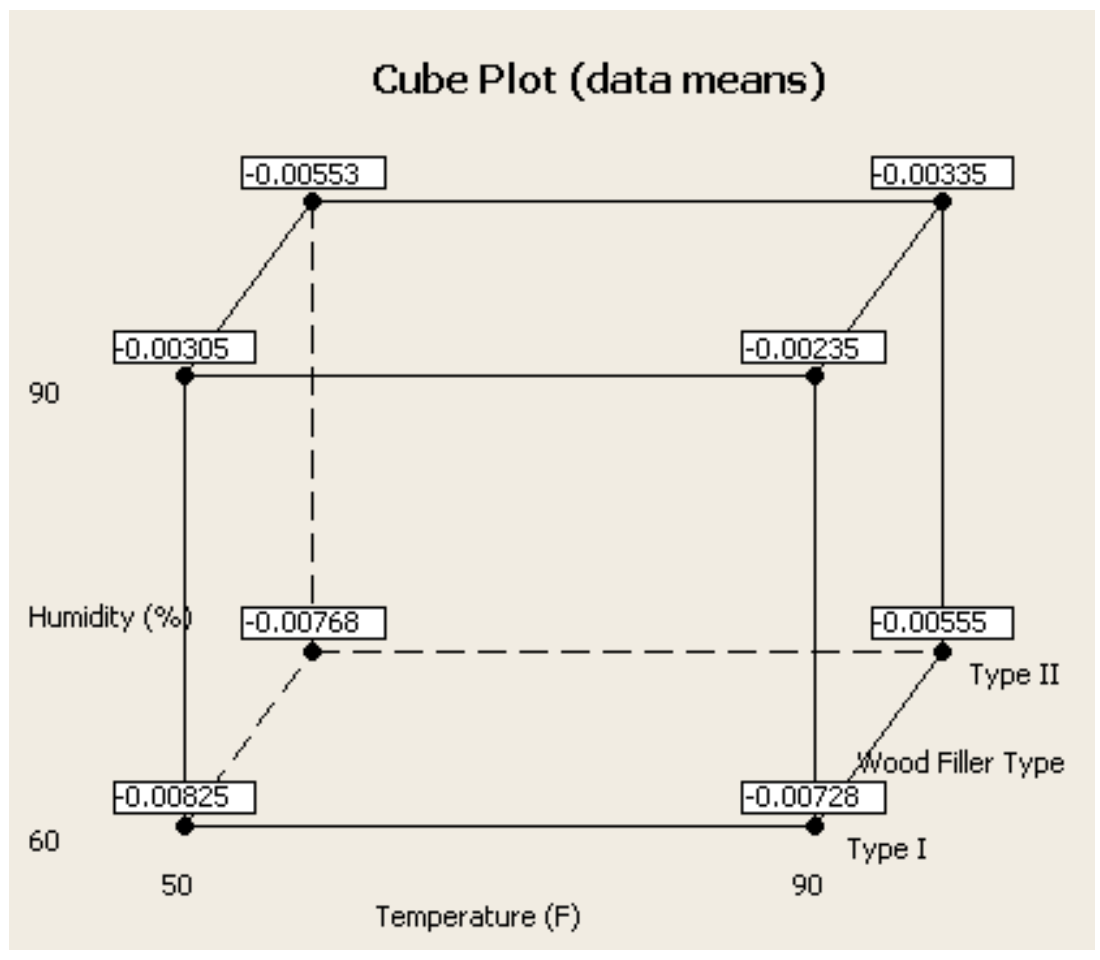

Figure 4.9: Cube Plot for Red Maple

\subsection{Actual Sample Testing Results}

Hardwood samples shown in figure 4.10 convey testing samples once completed.

Each run corresponds to a different set of environmental testing conditions and each tray includes 8 samples with each defect. 


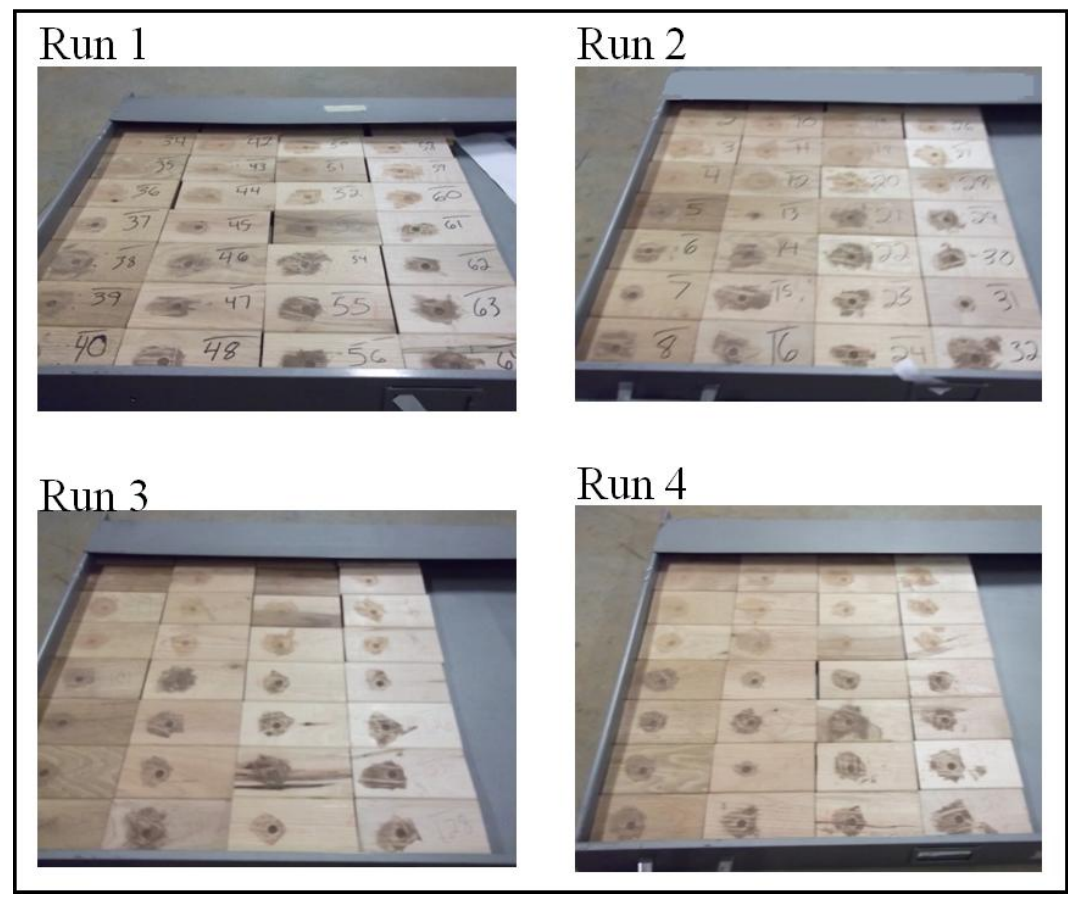

Figure 4.10: Actual Sample Testing Results 


\section{CHAPTER 5: ANALYSIS, CONCLUSIONS, \& FUTURE WORK}

Chapter V analyzes and concludes on significant results presented in Chapter IV as well as information provided in the appendices. Data was deemed significant if a terms p-value was less than an alpha value of .05. All ANOVA summaries were generated when conducting the DOE in Minitab analysis software. Cube plots are helpful in visually conveying results of replicate averages. Educational based conclusions are presented based on supporting research. Future work and recommendations are then offered at the closing stages of the chapter. This chapter begins with an analysis of statistical testing data.

\subsection{Analysis of Moisture Content Data}

Data shown in figure 4.1 represents moisture contents recorded throughout testing. The purpose of recording moisture content was to observe samples, which could lead to justification of unexplained RS during analysis. A bake-out was conducted by Shaw personnel prior to testing, while a surface meter was used to record surface moisture throughout testing. In figure 4.1 data shown in black represents bake-out results for each hardwood sample along with an average for all samples, data shown in orange represents individual moisture contents with the corresponding overall average of data prior to entering the control chamber, data shown in yellow represents individual moisture contents with the corresponding overall average of data after exiting the control chamber, and data shown in green represents individual moisture contents with the corresponding overall average of data once arriving at WCU. Bake-out results showed that the average moisture percent for all hardwood samples was around 6.8 percent 
moisture; with the highest moisture content sample containing around 9 percent moisture and the lowest containing around 5.7 percent. Surface meter results, prior to chamber entry, showed that the average moisture percent for all hardwood samples was around 7.7 percent moisture; with the highest moisture content sample containing around 9.9 percent moisture and the lowest containing around 5.8 percent. Surface meter results, after exiting chamber, showed that the average moisture percent for all hardwood samples was around 8 percent moisture; with the highest moisture content sample containing around 10.1 percent moisture and the lowest containing around 5.3 percent. Surface meter results, upon arriving at $\mathrm{WCU}$, showed that the average moisture percent for all hardwood samples was around 7.1 percent moisture; with the highest moisture content sample containing around 8.8 percent moisture and the lowest containing around 5.6 percent.

\subsection{Analysis of Design of Experiments Data}

\section{White Oak}

Neither main effects nor interactions were deemed significant in the white oak. Observe the cube plot shown in figure 4.3. The worst case of RS, in white oak, was when temperature was at 50 degrees Fahrenheit, relative humidity was 60 percent, and putty Type II was used. The best case of RS was when temperature was at 90 degrees Fahrenheit, relative humidity was 60 percent, and putty Type I was used. Averages, at different variable combinations, are shown throughout figure 4.3 for the white oak species. 


\section{Red Oak}

An ANOVA summary conveying significance, for the red oak specie terms, is

shown in figure 5.1. Results from the red oak DOE show that humidity was the only term found to be significant when the p-value of 0.021 was compared to an alpha value of .05 . Significance was found by identifying the p-value of a term to be less than the designated alpha value of .05. The effect of humidity was around 0.004 of an inch.

\begin{tabular}{|lrrrrr|}
\hline Term & Effect & Coef & SE Coef & T & P \\
Constant & & -0.004803 & 0.000798 & -6.02 & 0.000 \\
Temperature (F) & 0.000906 & 0.000453 & 0.000798 & 0.57 & 0.575 \\
\hline Humidity (₹) & -0.003931 & -0.001966 & 0.000798 & -2.46 & 0.021 \\
\hline Wood Filler Type & -0.000431 & -0.000216 & 0.000798 & -0.27 & 0.789 \\
Temperature (F) *Humidity (\$) & -0.000194 & -0.000097 & 0.000798 & -0.12 & 0.904 \\
Temperature (F) *Wood Filler TYpe & -0.001569 & -0.000784 & 0.000798 & -0.98 & 0.336 \\
Humidity (*) *Wood Filler TYpe & 0.000969 & 0.000484 & 0.000798 & 0.61 & 0.550 \\
Temperature (F) *Humidity (\$)* & -0.000944 & -0.000472 & 0.000798 & -0.59 & 0.560 \\
Wood Filler TYpe & & & & & \\
\hline
\end{tabular}

Figure 5.1: ANOVA Summary Conveying Significance for Red Oak

A cube plot, for the red oak species, is shown in figure 4.5. The worst case of RS, in red oak, was when temperature was at 50 degrees Fahrenheit, relative humidity was 90 percent, and putty Type I was used. The best case of RS was when temperature was at 90 degrees Fahrenheit, relative humidity was 60 percent, and putty Type I was used. Averages, at different variable combinations, are shown throughout figure 4.5.

The main effects plot for the term humidity, in the red oak species, is shown in figure 5.2. When going from 60 percent relative humidity to 90 percent relative humidity there was an increase of approximately 0.004 of an inch in RS. RS was less in the red oak species when humidity was at 60 percent versus 90 percent. 


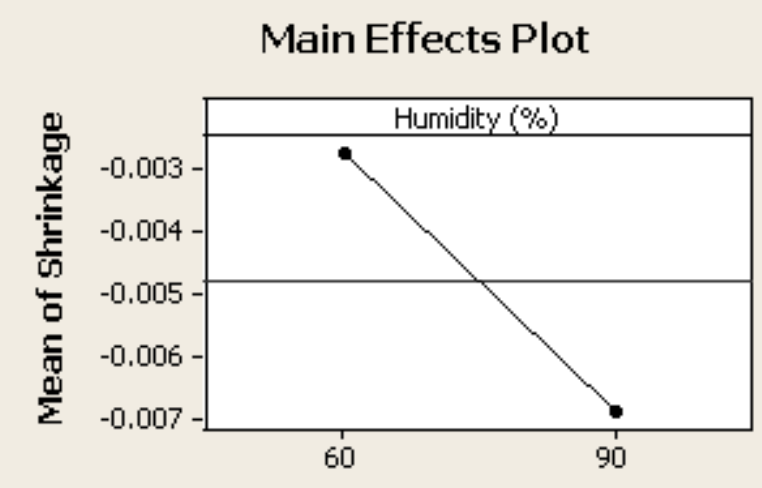

Figure 5.2: Main Effects Plot for Humidity in Red Oak

\section{Hickory}

An ANOVA summary conveying significance, for the hickory specie terms, is shown in figure 5.3. Results from the hickory DOE show that humidity, wood putty type, and the interaction between humidity and wood putty type were found to be significant variables when $\mathrm{p}$-values of $0.016,0.040$, and 0.000 were compared to an alpha value of .05. The effect of humidity was around 0.004 of an inch, putty type was 0.003 of an inch, and interaction between humidity and wood putty type was around 0.006 of an inch.

\begin{tabular}{|c|c|c|c|c|c|}
\hline Term & Effect & Coef & SE Coef & $\mathrm{T}$ & $\mathrm{P}$ \\
\hline Constant & & -0.005244 & 0.000692 & -7.57 & 0.000 \\
\hline Temperature $(F)$ & 0.001175 & 0.000587 & 0.000692 & 0.85 & 0.404 \\
\hline Humidity $\left(\frac{5}{8}\right)$ & 0.003600 & 0.001800 & 0.000692 & 2.60 & 0.016 \\
\hline Wood Filler Type & -0.003000 & -0.001500 & 0.000692 & -2.17 & 0.040 \\
\hline Temperature (F) *Humidity (온 & 0.000587 & 0.000294 & 0.000692 & 0.42 & 0.675 \\
\hline Temperature $(F)$ *tood Filler Type & -0.000713 & -0.000356 & 0.000692 & -0.51 & 0.612 \\
\hline Humidity (혹)*Wood Filler Type & 0.005963 & 0.002981 & 0.000692 & 4.31 & 0.000 \\
\hline $\begin{array}{l}\text { Temperature (F) *Humidity }(\stackrel{3}{3}) \text { " } \\
\text { Wood Filler TYpe }\end{array}$ & -0.000625 & -0.000313 & 0.000692 & -0.45 & 0.656 \\
\hline
\end{tabular}

Figure 5.3: ANOVA Summary Conveying Significance for Hickory

A cube plot, for the hickory species, is shown in figure 4.7. The worst case of RS, in hickory, was when temperature was at 50 degrees Fahrenheit, relative humidity was 90 
percent, and putty Type I was used. The best case of RS was when temperature was at 90 degrees Fahrenheit, relative humidity was 60 percent, and putty Type I was used. Averages, at different variable combinations, are shown throughout figure 4.7.

The main effects plots for the terms humidity and wood putty type, in the hickory species, are shown in figure 5.4. When going from 60 percent relative humidity to 90 percent relative humidity there was a decrease of approximately 0.004 of an inch in RS. RS was less in the hickory species when humidity was at 90 percent versus 60 percent. When going from Type I wood putty to Type II wood putty there was an increase of 0.003 of an inch in RS. RS was less in the hickory species when Type I putty was used versus Type II.

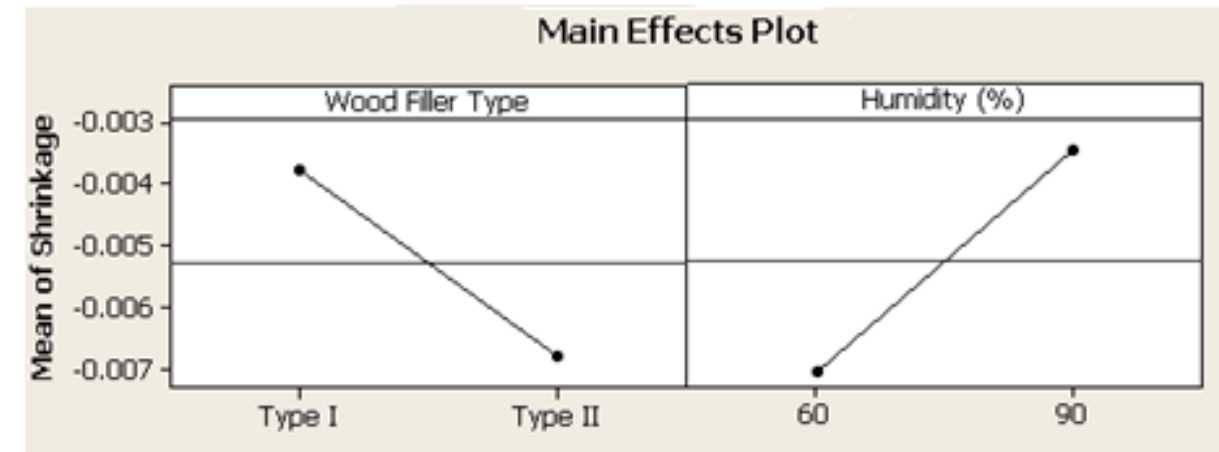

Figure 5.4: Main Effect Plots for Humidity \& Putty Type in Hickory

The interaction plot for the interaction between humidity and wood putty type, in the hickory species, is shown in Figure 5.5. Notice RS is at its minimum when humidity is at 90 percent and putty Type II is used. Comparable results could be given with humidity at 60 percent and putty Type I. Notice RS is the most with humidity at 60 percent and putty Type II. Type I wood putty was noticeably more stable than Type II wood putty. 


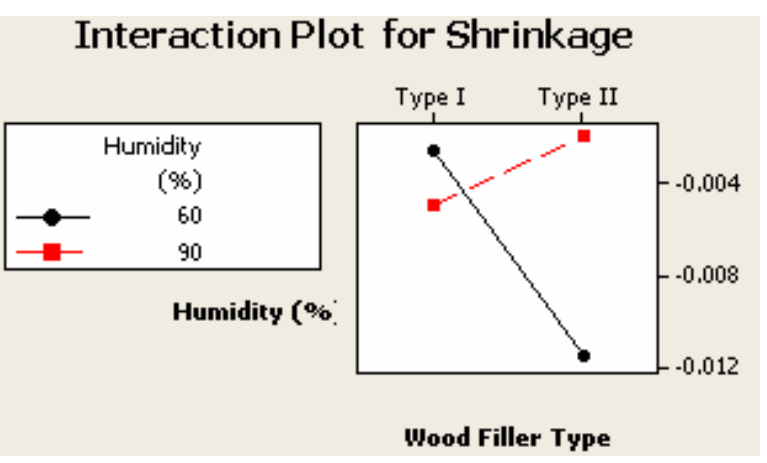

Figure 5.5: Interaction Plot for Humidity \& Putty Type in Hickory

\section{Red Maple}

An ANOVA summary conveying significance, for the red maple specie terms, is

shown in figure 5.6. Results from the red maple DOE show that humidity was the only term found to be significant when the p-value of 0.009 was compared to an alpha value of .05. The effect of humidity was around 0.0036 of an inch.

\begin{tabular}{|c|c|c|c|c|c|}
\hline Term & Effect & Coef & SE Coef & $\mathrm{T}$ & $\mathrm{P}$ \\
\hline Constant & & -0.005378 & 0.000634 & -8.48 & 0.000 \\
\hline Temperature (F) & 0.001494 & 0.000747 & 0.000634 & 1.18 & 0.251 \\
\hline Humidity (ํํ) & 0.003619 & 0.001809 & 0.000634 & 2.85 & 0.009 \\
\hline Jood Filler TYpe & -0.000294 & -0.000147 & 0.000634 & -0.23 & 0.819 \\
\hline Temperature $(F) *$ Humidity $(\$)$ & -0.000056 & -0.000028 & 0.000634 & -0.04 & 0.965 \\
\hline Temperature (F) NWood Filler TYpe & 0.000656 & 0.000328 & 0.000634 & 0.52 & 0.610 \\
\hline Humidity (\$) *tood Filler Type & -0.001444 & -0.000722 & 0.000634 & -1.14 & 0.266 \\
\hline $\begin{array}{l}\text { Temperature (F) *Humidity (\$)* } \\
\text { Wood Filler TYpe }\end{array}$ & 0.000081 & 0.000041 & 0.000634 & 0.06 & 0.949 \\
\hline
\end{tabular}

Figure 5.6: ANOVA Summary Conveying Significance for Red Maple

A cube plot, for the red maple species, is shown in figure 4.9. The worst case of RS, in red maple, was when temperature was at 50 degrees Fahrenheit, relative humidity was 60 percent, and putty Type I was used. The best case of RS was when temperature was at 90 degrees Fahrenheit, relative humidity was 90 percent, and putty Type I was used. Averages, at different variable combinations, are shown throughout figure 4.9. 
The main effects plot for the term humidity, in the red maple species, is shown in figure 5.7. When going from 60 percent relative humidity to 90 percent relative humidity there was a decrease of approximately 0.0036 of an inch in RS. RS was less in the red maple species when humidity was at 90 percent versus 60 percent.

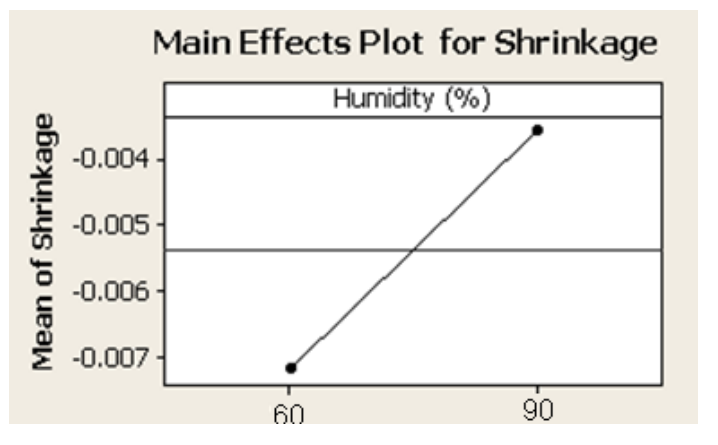

Figure 5.7: Main Effects Plot for Humidity in Red Maple

\subsection{Inferential Statistics}

Upon the first iterations of the statistical tests, a paired t-test was conducted to determine if the lowest point in every defect-void, recorded by a dial indicator, had statistically changed during transportation from AB-Tech to WCU. The paired t-test was conducted by entering dial indicator data into Microsoft Excel and performing the required statistical analysis. Results for the paired t-test are shown in Appendix J. The Null hypothesis was retained stating that means of both variables are statistically the same seeing that the "t Stat" value was less than the "t Critical". Statistically the same suggest there is no statistical evidence that a change occurred, in the samples, during transportation.

\subsection{Conclusions}

Humidity was found to be significant in three out of four species, of hardwood investigated, which included red oak, hickory, and red maple. Shaw might look to maintaining a consistent humidity within the plant. Temperature did not statistically have 
any significant impact on RS in any of the four species investigated. Temperature fluctuations in the plant should not affect RS. Wood putty type did in fact have an impact on RS in only the hickory species. Only one interaction was found that was significant, in hickory, throughout all four species investigated. More humidity may have induced the wood expansion, therefore, simulating less RS in hickory using Type II. Also, with low humidity the wood can dry, causing the wood to shrink and simulating a high RS value. The white oak species did not show any significant variables when analyzing the ANOVA summary.

Information included in the appendices is shown simply as data recorded during the different stages of testing to serve as supplemental information, which could justify unexplained RS. Notice temperature/humidity data, shown in Appendix A, recorded while both types of putty were mixed at consistent velocities and times. Appendix B, Appendix $C$, Appendix $D$, and Appendix $E$ confirm that environmental conditions were met during each testing run. Appendix F, Appendix $G$, Appendix $H$, and Appendix I convey transportation/storage temperature and humidity data. Refer to the desired appendix for relevant information.

\subsection{Future Work \& Recommendations}

Future work might include the same study to generate data over time, where a regression analysis can be performed to create a prediction equation of $\mathrm{RS}$, given the known process input variables. Shaw might also look at studying a larger population to see if results are similar to results from this study. Machine upgrades at Shaw should include investments towards a CMM to install in the Bryson City plant to check RS. Future work might include alternate material testing in search of the optimum wood 
putty, at different levels of environmental conditions, to find where different putty materials react most to humidity or filler type. In my opinion, I would not recommend a change in putty type unless if a large cost savings exist. There is no justification in completely switching putty materials.

Seeing that this research only dealt with water-based putty, it would be interesting to see how epoxy based putty compares, while considering complications of cleanup. This work established a standard testing method for comparing wood putties for industrialized settings by creating a consistent test cavity, test procedure, and analysis method. Future research should seek to eliminate the operator variable by replacing with automated assistance. This would enable statistical comparisons of force and application speeds. 
APPENDICES 


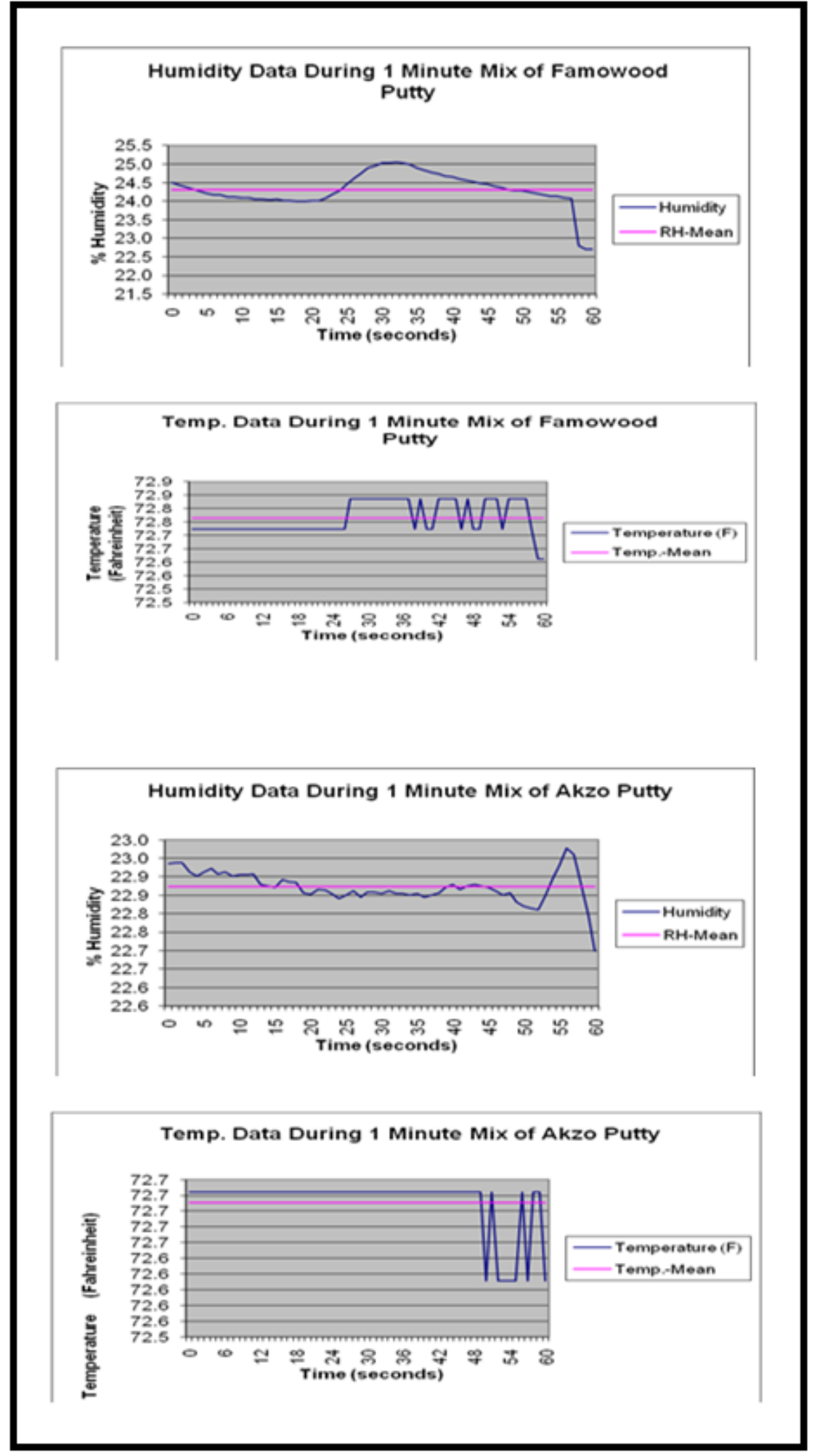



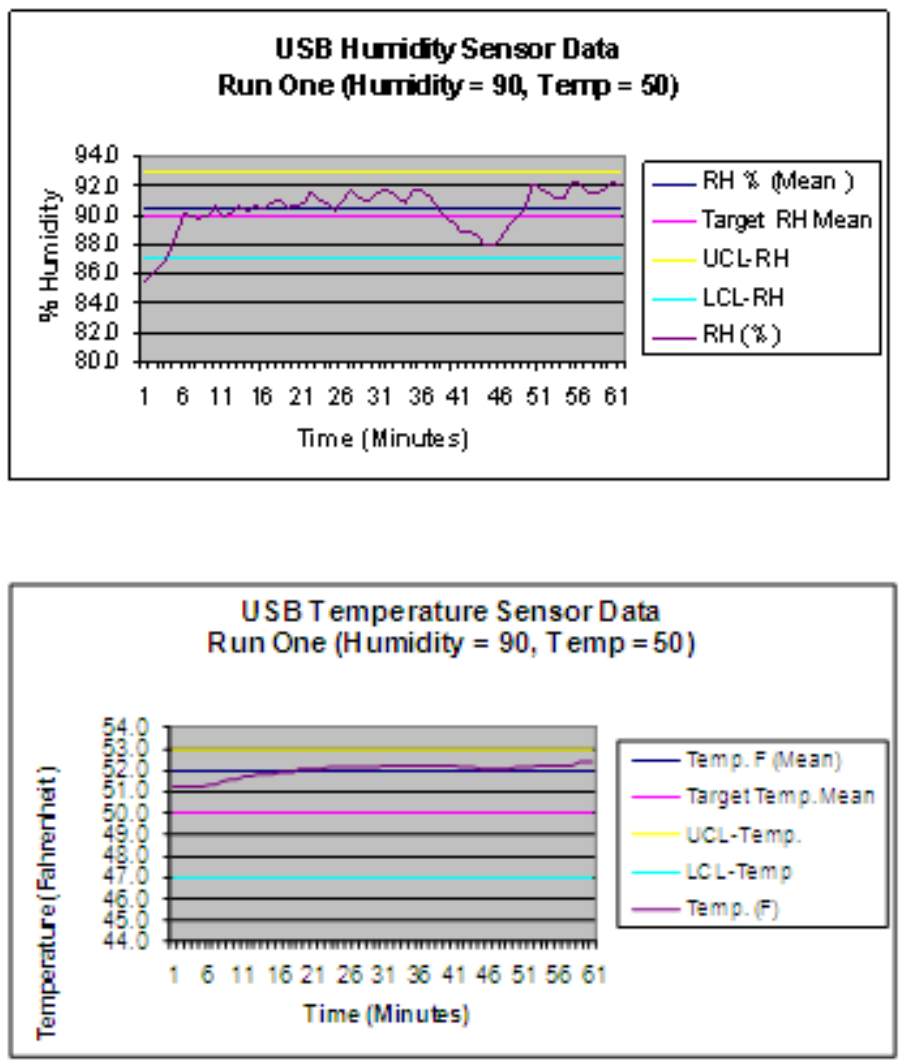

Run One (Humidity $90 \%$, Temperature 50 Deg. F)

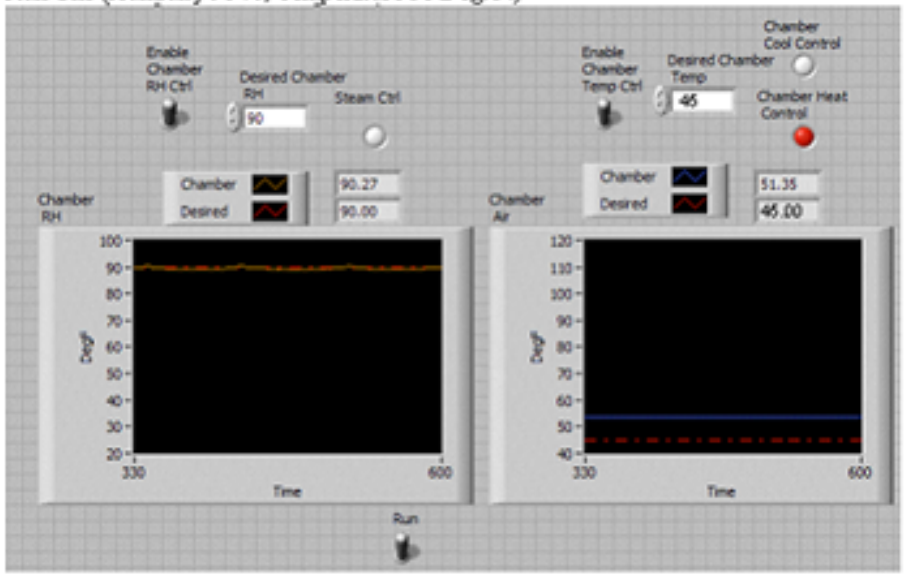




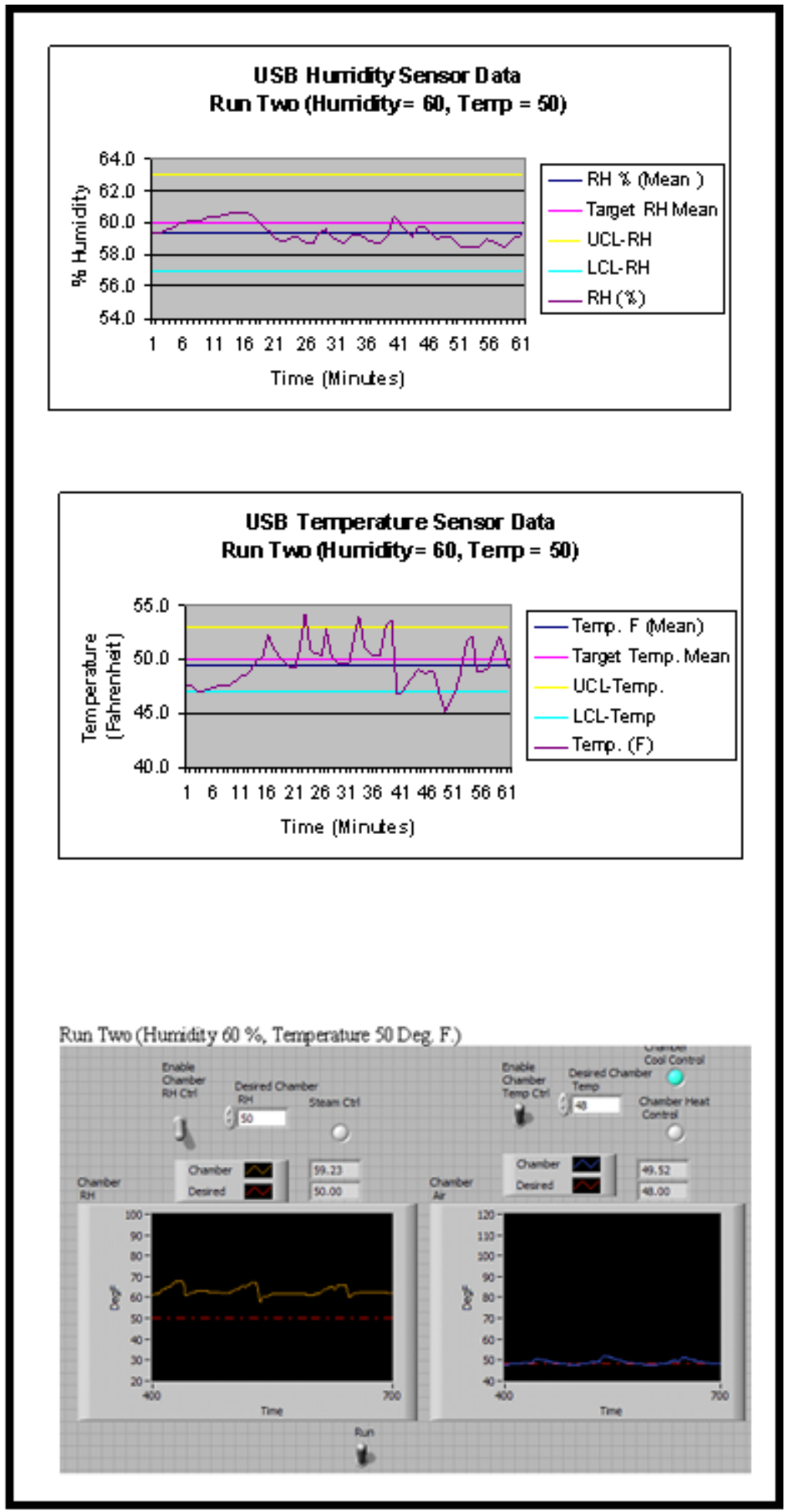



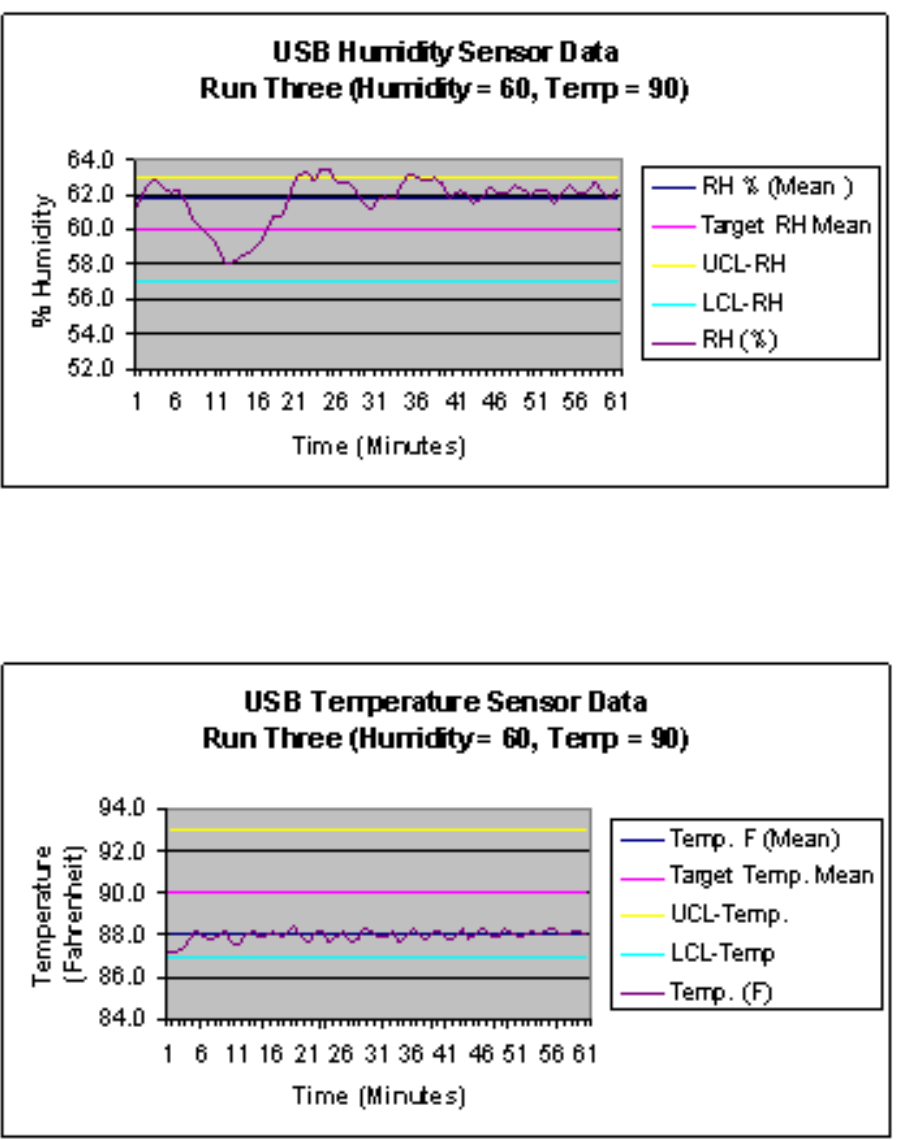

Run Three (Humidity $60 \%$, Temperature 90 Deg F.)

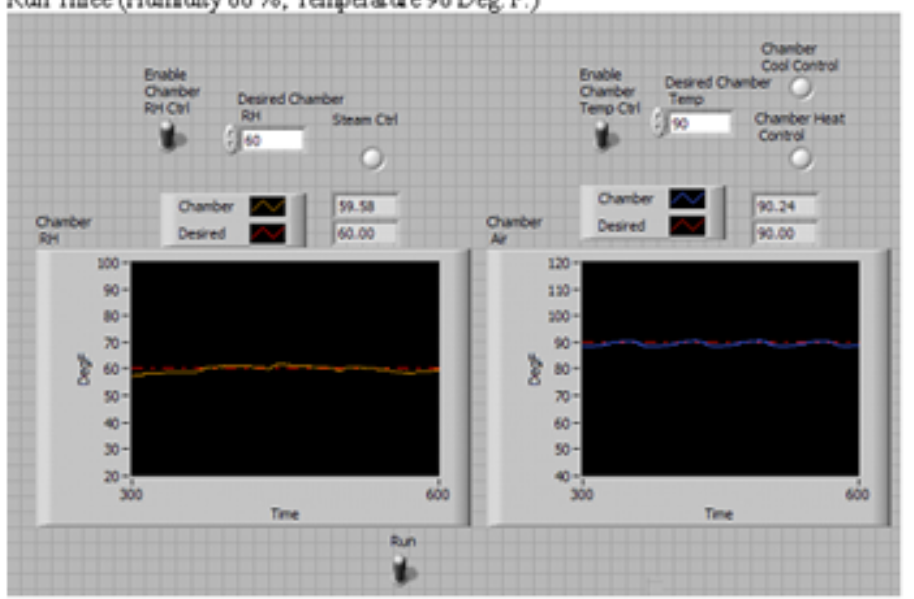




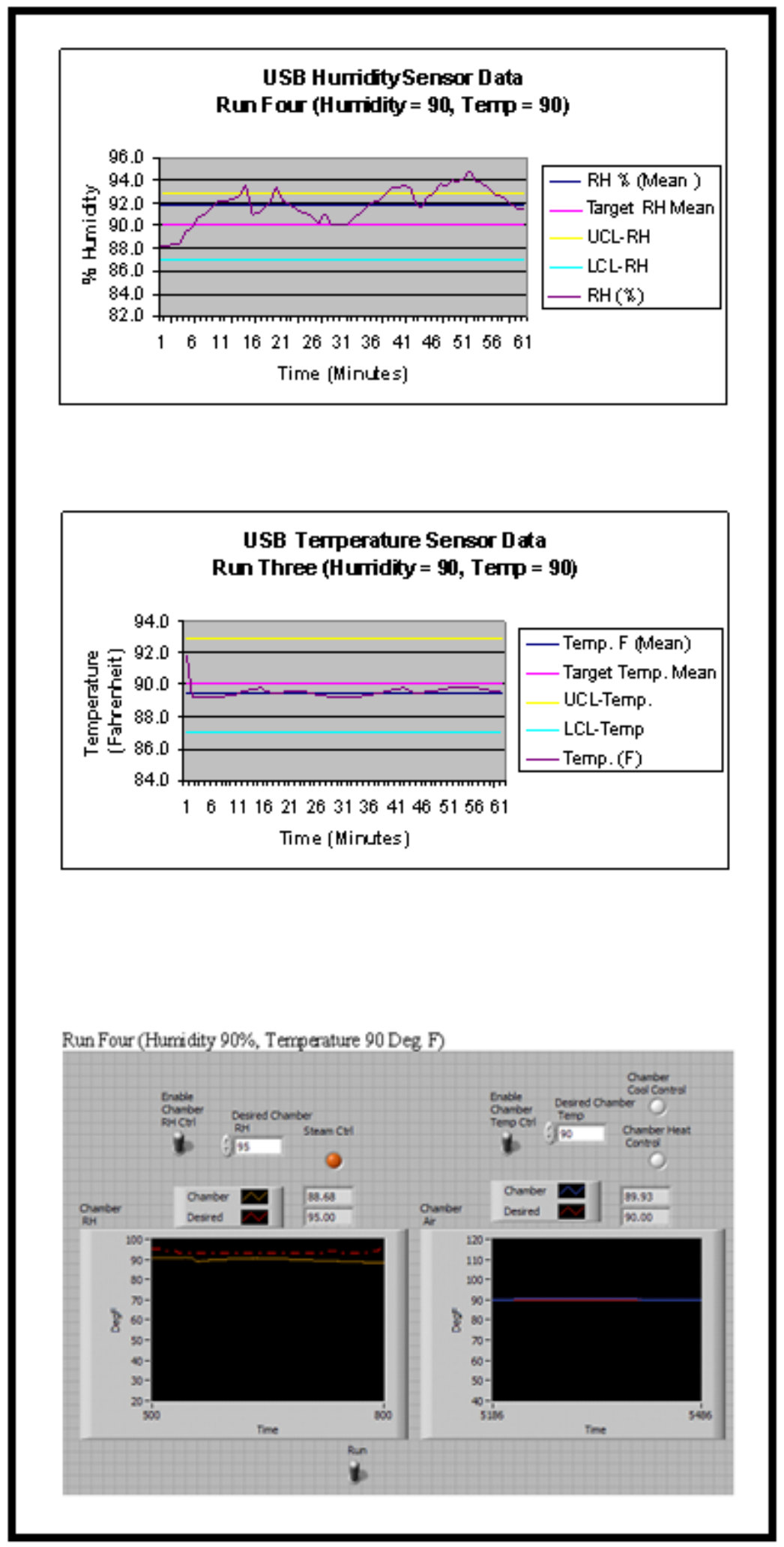


APPENDIX F: AB-TECH TEMPERATURE \& HUMIDITY DATA, AFTER TESTING

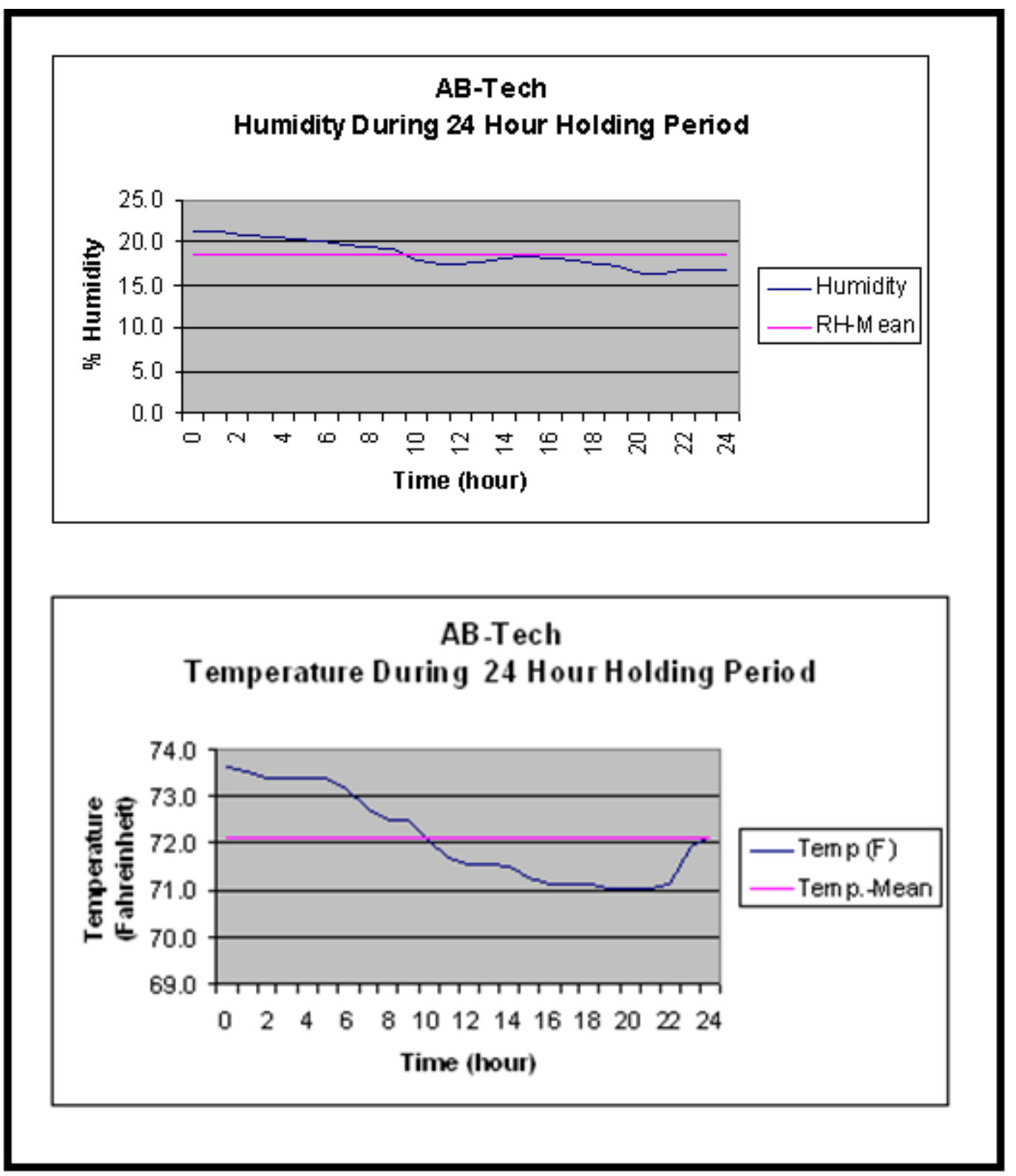




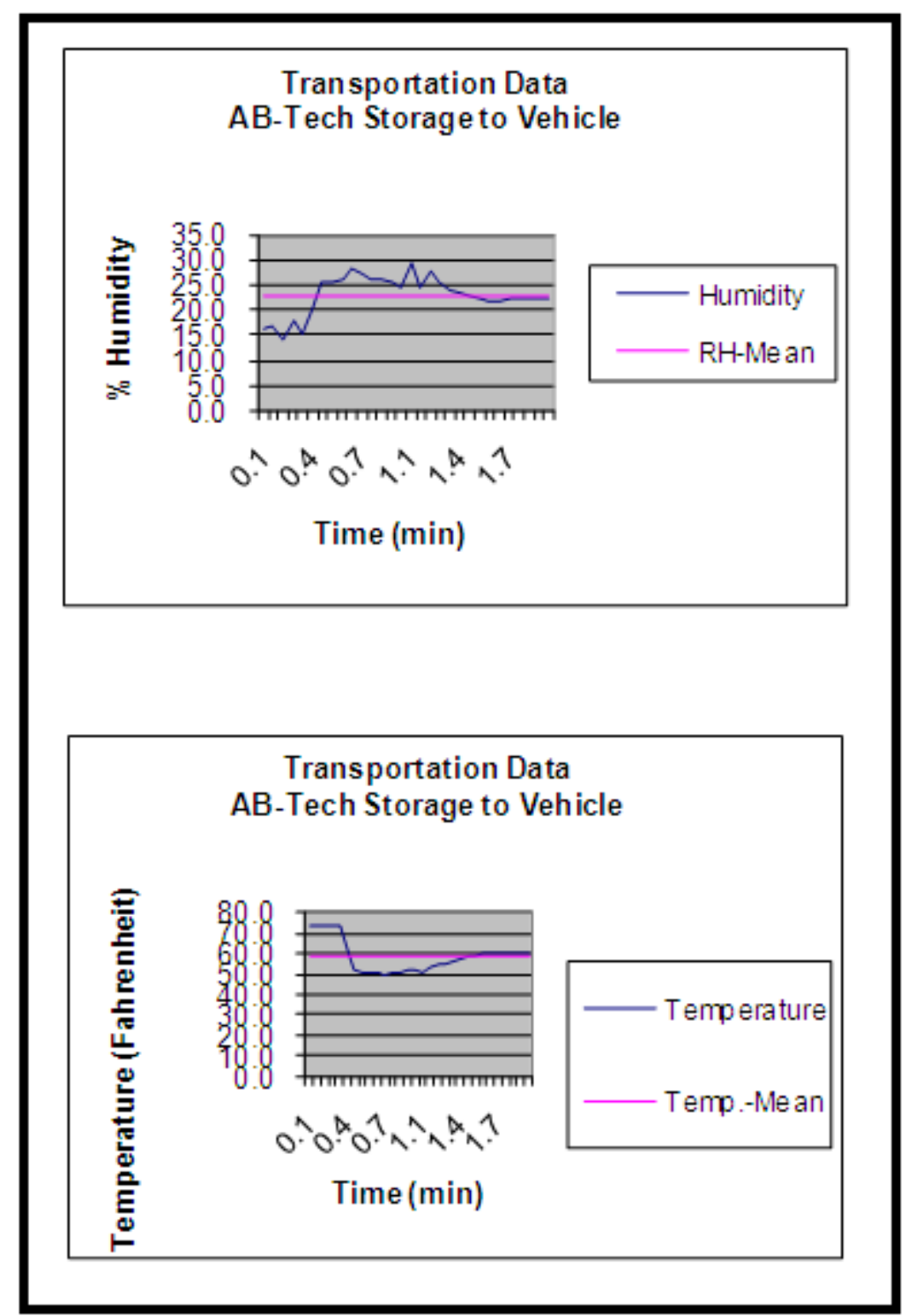




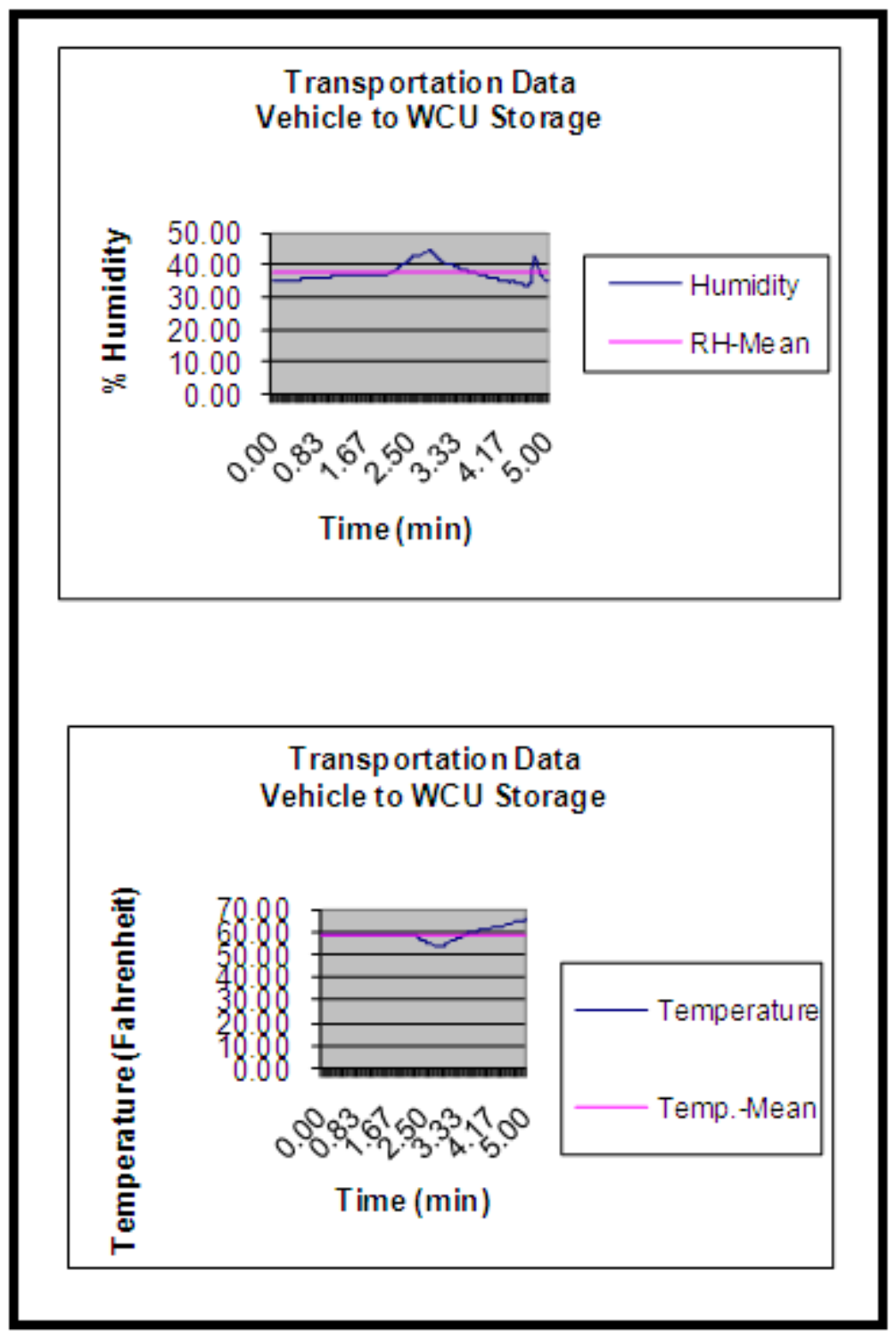


APPENDIX I: TEMPERATURE \& HUMIDITY STORAGE DATA, AFTER

\section{TRANSPORTATION}

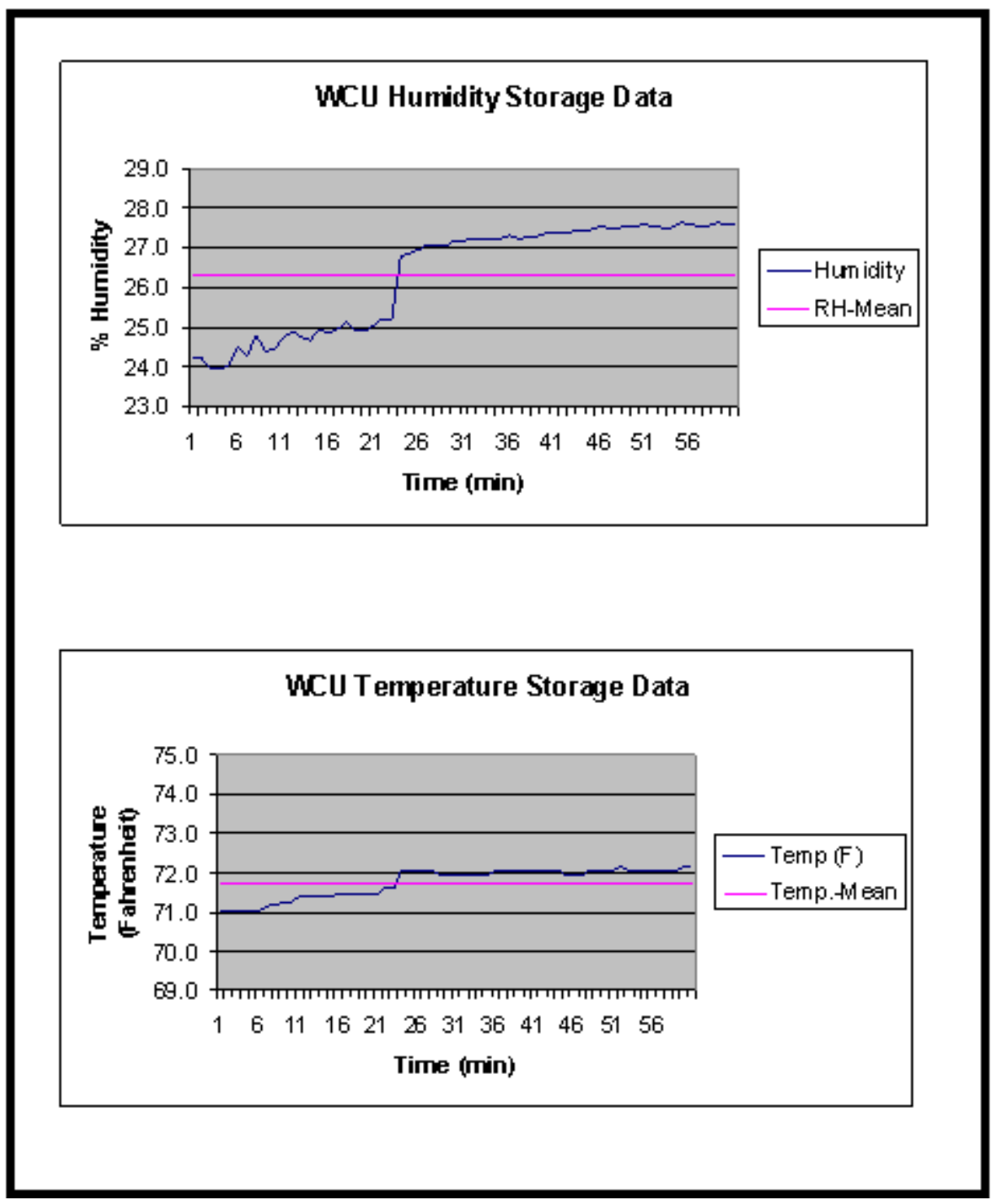




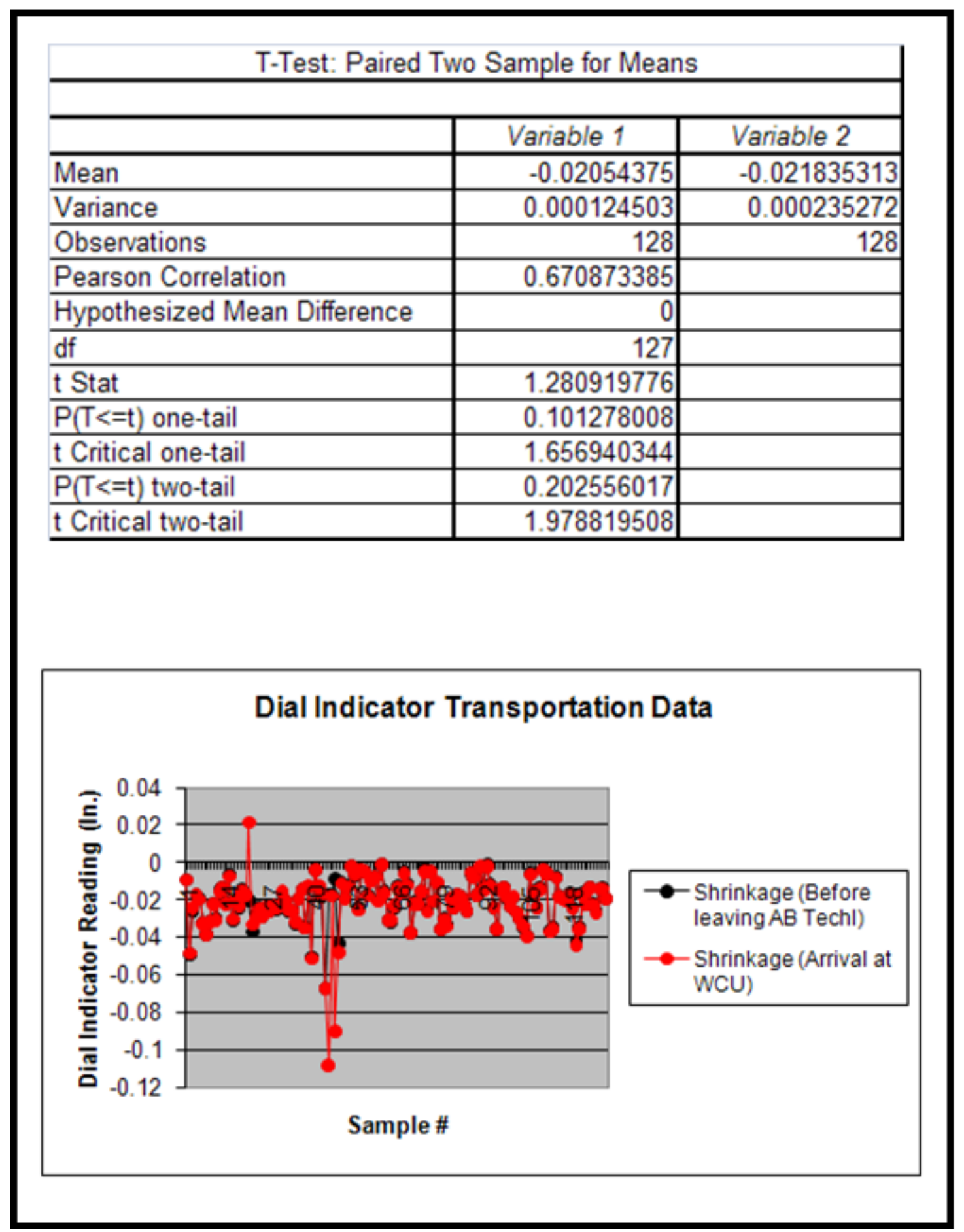




\section{BIBLIOGRAPHY}

Adams, D. M., \& Haynes, R. W. (2007). Resources and market projections for forest policy development. Dordrecht, The Netherlands: Springer.

Dotson, C., Harlow, R., \& Thompson, R. (2003). Fundamentals of dimensional metrology $\left(4^{\text {th }}\right.$ ed.). Clifton Park, New York: Delmar Learning.

Evans, J.R., \& Lindsay, W.M. (2005). The management and control of quality (6 ${ }^{\text {th }}$ ed.). Eagan, Minnesota: Thomson-West.

Feirer, J. L. (1963). Woodworking for industry. Peoria, Illinois: Chas. A. Bennett Co., Inc.

Feirer, J. L. (1975). Wood materials and processes. Peoria, Illinois: Chas. A. Bennett Co., Inc.

Grad, F. P., Rathjens, G. W., Rosenthal, A. J. (1971). Environmental control: priorities, policies, and the law. New York, New York: Columbia University Press.

(Holechek, J. L., Cole, R. A., Fisher, J.T., \& Valdez, R. (2003). Natural resources ecology, economics, and policy ( $2^{\text {nd }}$ ed.). Upper Saddle River, New Jersey: Pearson Education.

Jiju, A. (2004). Design of experiments for engineers and scientist. Saint Louis, Missouri: Elsevier Publishing.

Kamrany, N. M. (1974). Technology: Measuring the socioeconomic impact of manufacturing automation. Socio-Economic Planning Sciences, 8(5), 281-292. doi:DOI: 10.1016/0038-0121(74)90013-5 
Klein, J. A. \& Leung, K., C. (1976). The environmental control industry an analysis of conditions and prospects for the pollution control equipment industry. New York, New York: Allanheld, Osmun \& Co.

Lindenmayer, D. B., \& Franklin, J. F. (2003). Towards forest sustainability. Washington, District of Columbia: Island Press.

U.S. Department of Agriculture (2007). The encyclopedia of wood. New York, New York: Skyhorse Publishing, Inc.

Venuvinod, P. K. \& Ma, W. (2004). Rapid prototyping laser-based and other technologies. Norwell, Massachusetts: Kluwer Academic Publishers. 


\section{REFERENCES}

AkzoNobel (2010). Wood Finishes and Adhesives. Retrieved December 3, 2010 from, AkzoNobel Web site: http://www.akzonobel.com/

Ball, A. K., Ferguson, C., \& Miceli, F. (2008, April). A low cost environmental test chamber for teaching engineering and technology students. Paper presented at the American Society for Engineering Education Southeastern Section Conference on Engineering Education, Memphis, TN. Abstract retrieved from http://icee.usm.edu/icee/conferences/Conference\%20Files/ASEE2008/asee_2008_ main.htm

ECLECTIC (2010). Wood and Grain Fillers. Retrieved December 3, 2010 from, Eclectic Products Web site: http://www.eclecticproducts.com/famowood.htm

Lewis, M. (2008). Sold! shaw purchases zickgraf. The Franklin Press. Retrieved from http://thefranklinpress.com/articles/2008/07/04/news/01news.txt

Microsoft (2011). Details at a glance. Retrieved December 3, 2010 from, Microsoft Store Web site:

http://www.microsoftstore.com/store/msstore/pd/productID.216445700?WT.mc

Shaw Floors (2003). Shaw History. Retrieved November 23, 2010

from, Shaw Industries Group, Inc. Web site: http://shawfloors.com/ 